\title{
S3C, PROTOTIPOS DE VIVIENDA CONSTRUIDOS POR COMPONENTES COMPATIBLES
}

\author{
(S3C, HOUSING PROTOTYPES BUILT BY COMPATIBLE COMPONENTS)
}

J. Miguel Reyes González, A rquitecto

$193-9$

\section{RESUMEN}

¿Qué es la construcción por componentes compatibles? ¿En qué consiste?

¿Cuáles son sus planteamientos?

¿Qué resultados y respuestas aporta?

¿Qué consecuencias e implicaciones conlleva?

$A$ estas y otras cuestiones relacionadas con el tema tratan de dar respuesta estas páginas, pero recurriendo para ello no a definiciones y generalidades que podrian sucumbir en el mundo de las disquisiciones teóricas, sino haciendo referencia a prototipos y proyectos concretos de vivienda realizados en la última década que servirán para, a partir de su descripción exponer las particulares condiciones que de los mismos se desprenden:

- Metodológicas: "órdenes abiertos".

- Tecnológicas: "componentes compatibles".

- De mercado: "prefabricación abierta".

- Transformación: zactualización?
SUMMARY

What is the construction by compatible components about? Which are its plants?

Which results and answers does it add?

Which consequences and implications does it lead to?

To these other questions related with the subject, this work tries to give answer, not by definitions and generalities which would fail in the field of a theoretical disquisition but by a review of determined prototypes and projects of dwellings built during the last ten years, which will lead us, on base of its descriptions, to expose out in particular:

- Methodological conditions: "open orders".

- Technological conditions: "compatible compounds".

- Trade conditions: "open prefabrication".

- Transformation conditions: actualization?

\section{INTRODUCCION}

Se ha venido especulando mucho desde los años 70 en los círculos allegados a la crítica y enseñanza de la arquitectura, sobre la posibilidad o no de poner en práctica las extremas teorías arquitectónicas de los años 60, en cuanto a: "flexibilidad en arquitectura», "participación del usuario» y su asociación con las llamadas: "alta tecnología» (megaestructuras, metabolismo, Fuller, etc.) o, por el contrario, con la «tecnología-blanda», achacándole a «la crisis de la energía” y todas sus secuelas la no viabilidad de tales planteamientos, quedando éstos críticamente anclados en la propia "crisis".

No obstante, de entonces a esta parte, el tiempo no ha transcurrido en balde $y$, de forma casi anónima, al margen de «escuelas al uso» o críticas «premonitorias y locuaces», los acontecimientos han seguido su curso. Por ello, podemos encontrarnos ahora cómo han ido surgiendo ejemplos de construcción esporádicos y distanciados que, siguiendo aquellos principios, han sabido darles forma - ahora ya lejos de manifiestos, utopías e irrealidadesy cercanos, por el contrario, a la situación de cada país, que muestran unos resultados tangibles y realistas con las obvias posibilidades sociales y de mercado en que se encuentran inmersos. Unos por unos caminos, otros por otros, pero todos con un denominador común. 

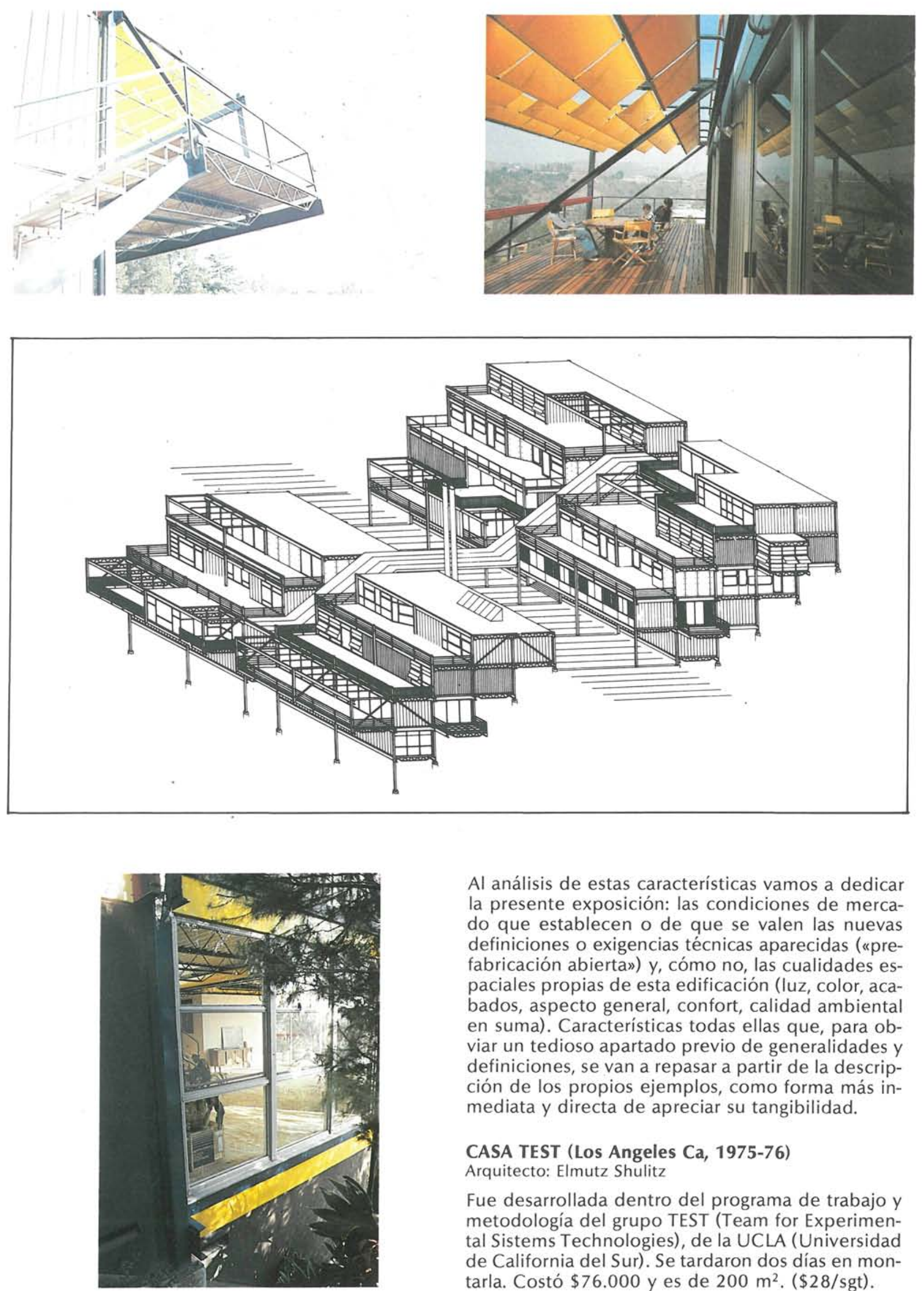

Al análisis de estas características vamos a dedicar la presente exposición: las condiciones de mercado que establecen o de que se valen las nuevas definiciones o exigencias técnicas aparecidas ("prefabricación abierta») y, cómo no, las cualidades espaciales propias de esta edificación (luz, color, acabados, aspecto general, confort, calidad ambiental en suma). Características todas ellas que, para obviar un tedioso apartado previo de generalidades y definiciones, se van a repasar a partir de la descripción de los propios ejemplos, como forma más inmediata y directa de apreciar su tangibilidad.

\section{CASA TEST (Los Angeles Ca, 1975-76)}

Arquitecto: Elmutz Shulitz

Fue desarrollada dentro del programa de trabajo y metodología del grupo TEST (Team for Experimental Sistems Technologies), de la UCLA (Universidad de California del Sur). Se tardaron dos días en montarla. Costó $\$ 76.000$ y es de $200 \mathrm{~m}^{2}$. (\$28/sgt). 

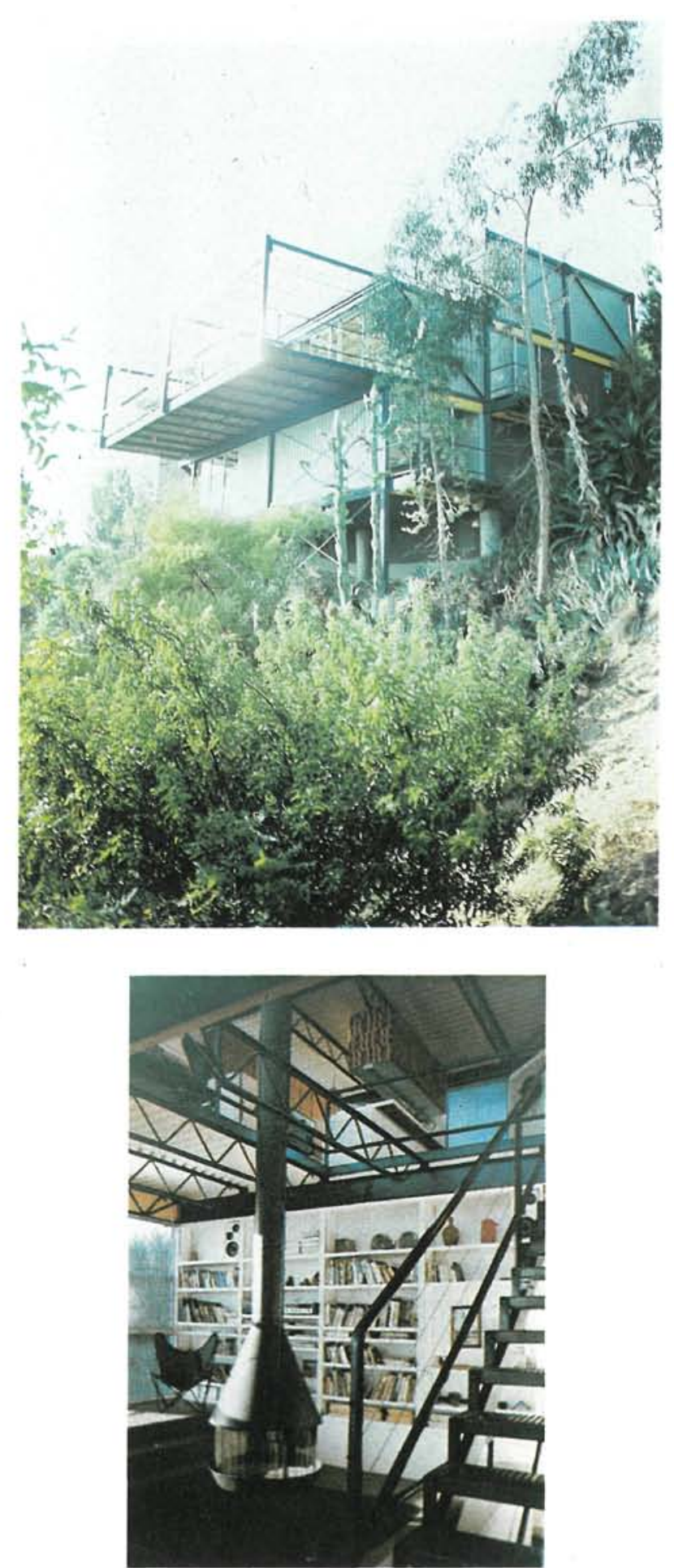

La construcción de la misma se realizó con componentes industriales estándar del mercado USA. En las figuras se puede apreciar cómo la necesaria compatibilidad de componentes ("prefabricación abierta») da lugar a una característica definición espacial y constructiva (organización y distribución) así como a unas cualidades ambientales. A su vez, hay que señalar en este aspecto la influencia de la ubicación geográfica en tal definición (clima templado y terreno inclinado): Terrazas, toldos, vegetación, vistas.

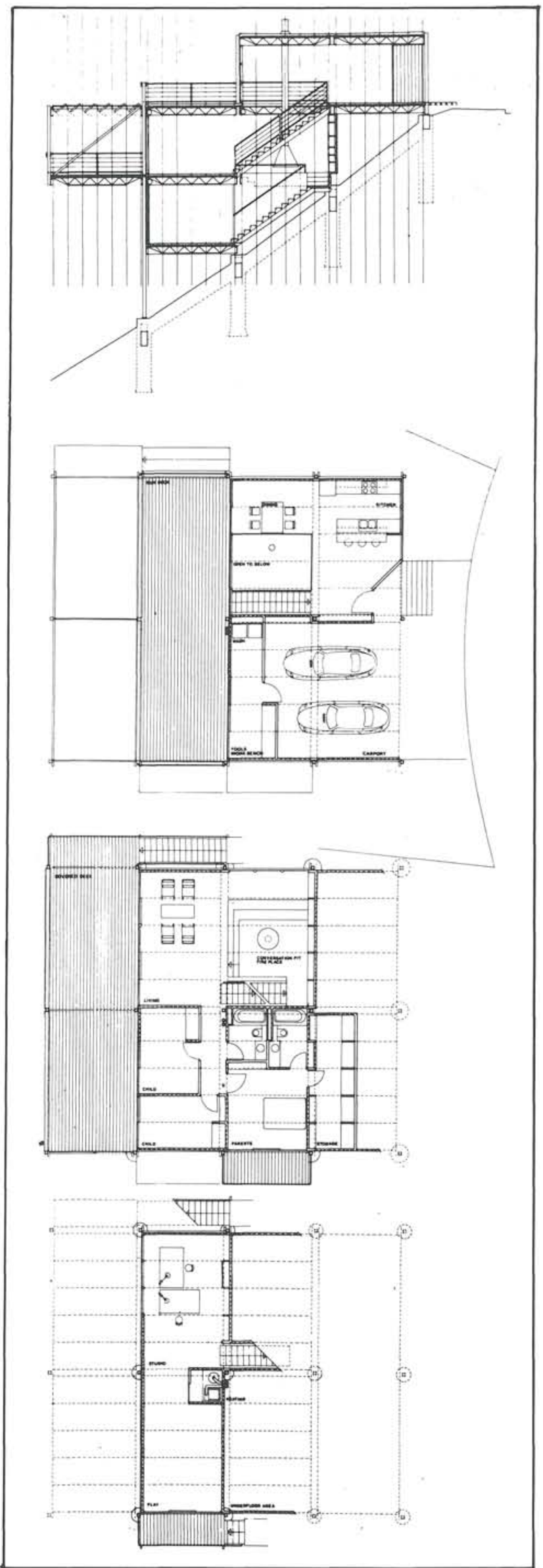




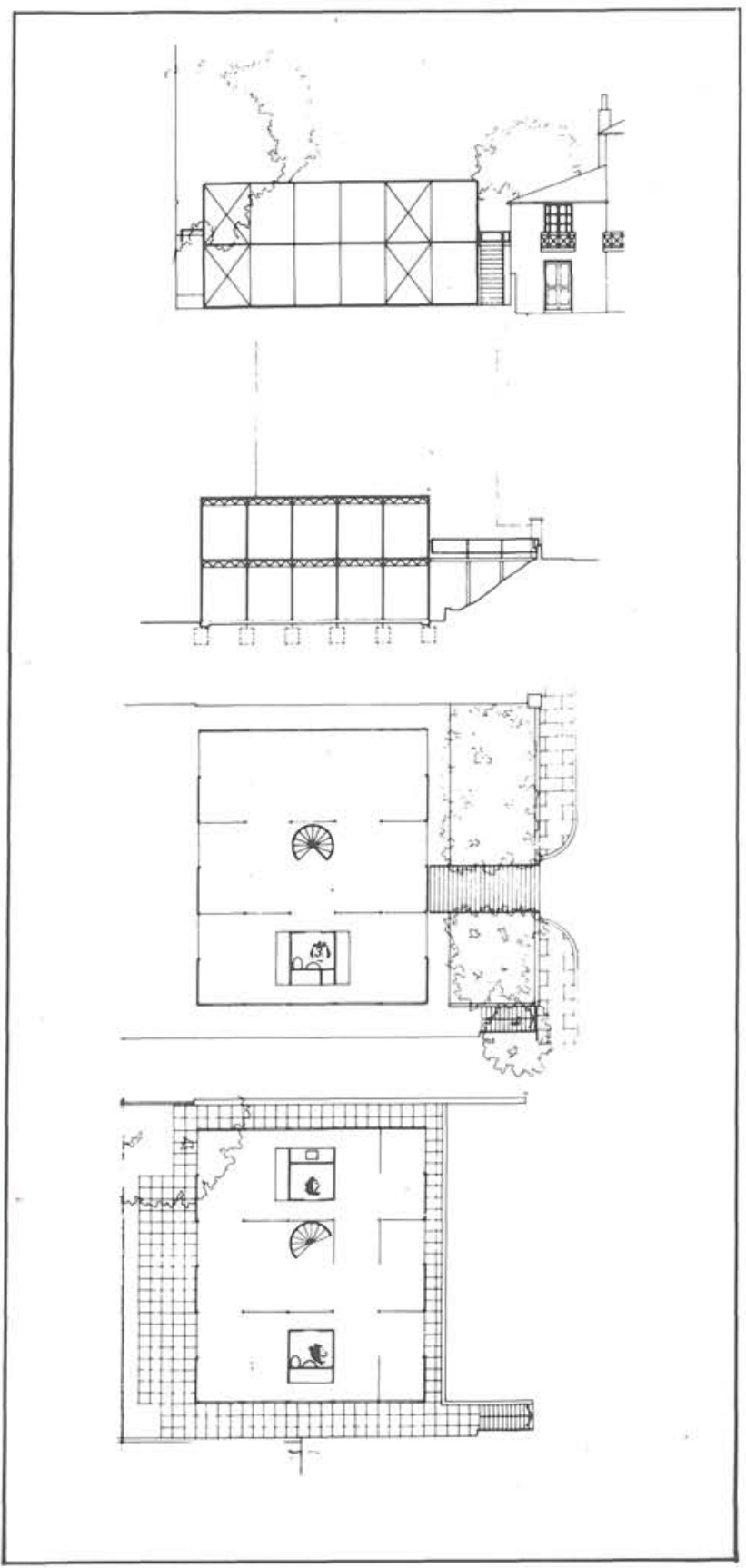

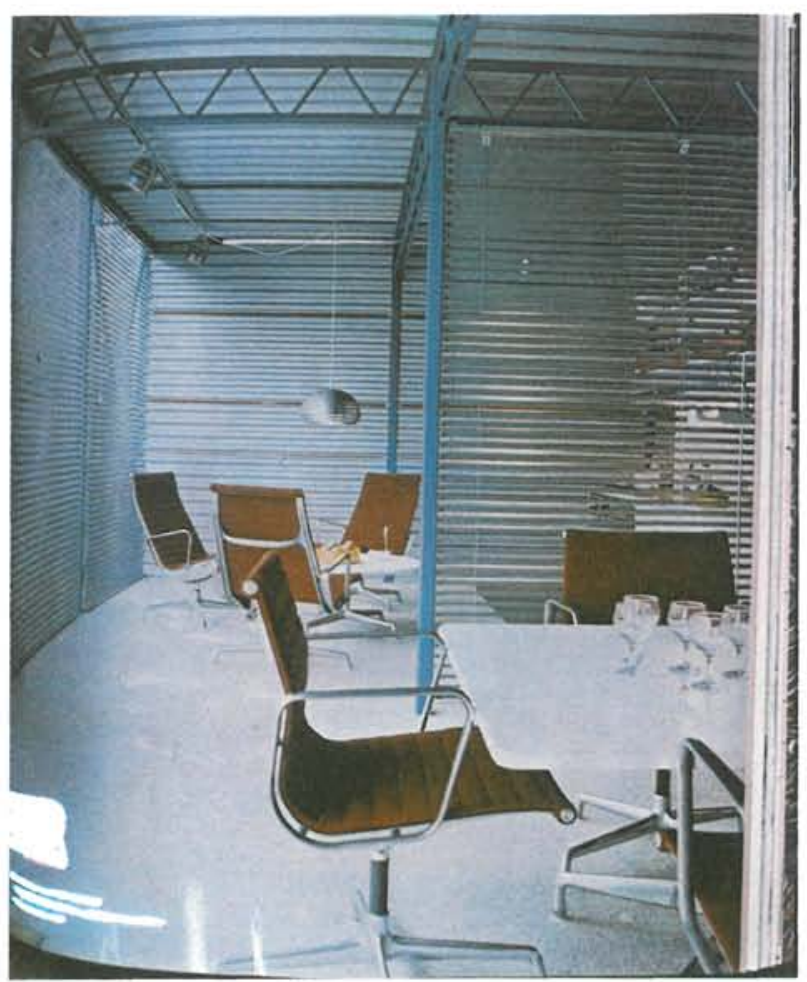

CASA HOPKINS (Londres, 1976)

Arquitecto: Michael Hopkins

En cuanto a su aspecto y definición ambiental, aparece fácil de relacionar con el tipo de construcción que plantea la casa TEST. Esto es debido a los componentes industriales utilizados (nuevamente estándares de construcción ligera). Sin embargo, su organización, aún haciendo propuestas de flexibilidad espacial, es fundamentalmente distinta ya que la primera plantea una cierta ley dinámica de agrupación, mientras esta segunda sólo lo hace como construcción individual, basada en los mismos principios de flexibilidad espacial del «contenedor universal de Mies V. der Roe». Se diferencia a su vez de éste en los susodichos procedimientos de construcción y montaje, que hacen de los mismos algo fácil de obtener y manejar, lejos por tanto de la sofisticación y especialización constructiva planteada desde aquél o los prototipos de J. Prouvé.
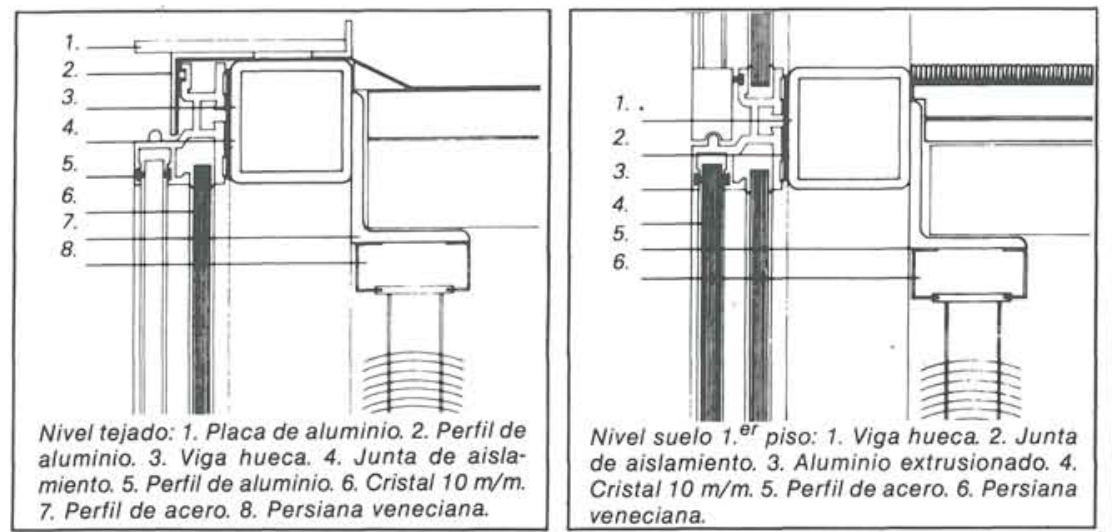

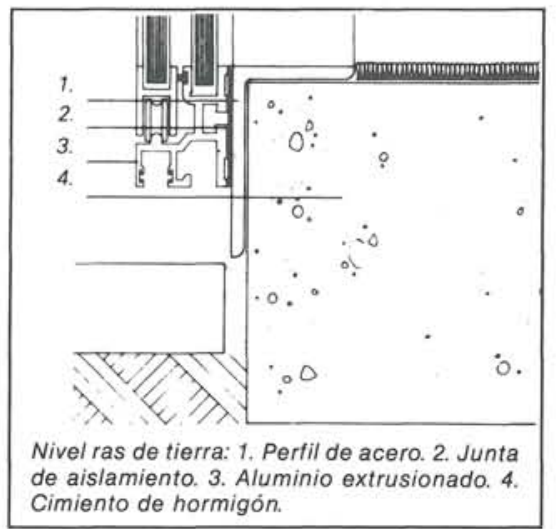


CASA TALLER NURMESMEMI (Helsinki, 1974-75) Arquitecto: Antty Nurmesmémi

Responde a un programa para alojamiento de tres familias aunque aquí aparece acondicionada para taller estudio.

Nuevamente, volvemos a encontrarnos en esta vivienda con situaciones y ambientes espaciales parecidos a los de las anteriores, pero con planteamientos de distribución y organización diferentes, ya que, aún apareciendo como unidad individual al igual que la Hopkins, sin embargo sustituye el concepto de agrupación de la TEST por el de comunidad.

Asi, dentro de un "contenedor espacial» surgen y se desarrollan diferentes alturas y niveles, con un orden constructivo de un grado diferente al planteado desde dicho "contenedor» y que, aún dependiendo de éste, gozan de cierta flexibilidad respecto al mismo.

Vuelve a hacer aparición, por tanto, la «compatibilidad de componentes», todos ellos estándares industriales, denominador común del aspecto y resultados de estas construcciones, que, sin embargo, admiten la versatilidad de planteamientos anotada.
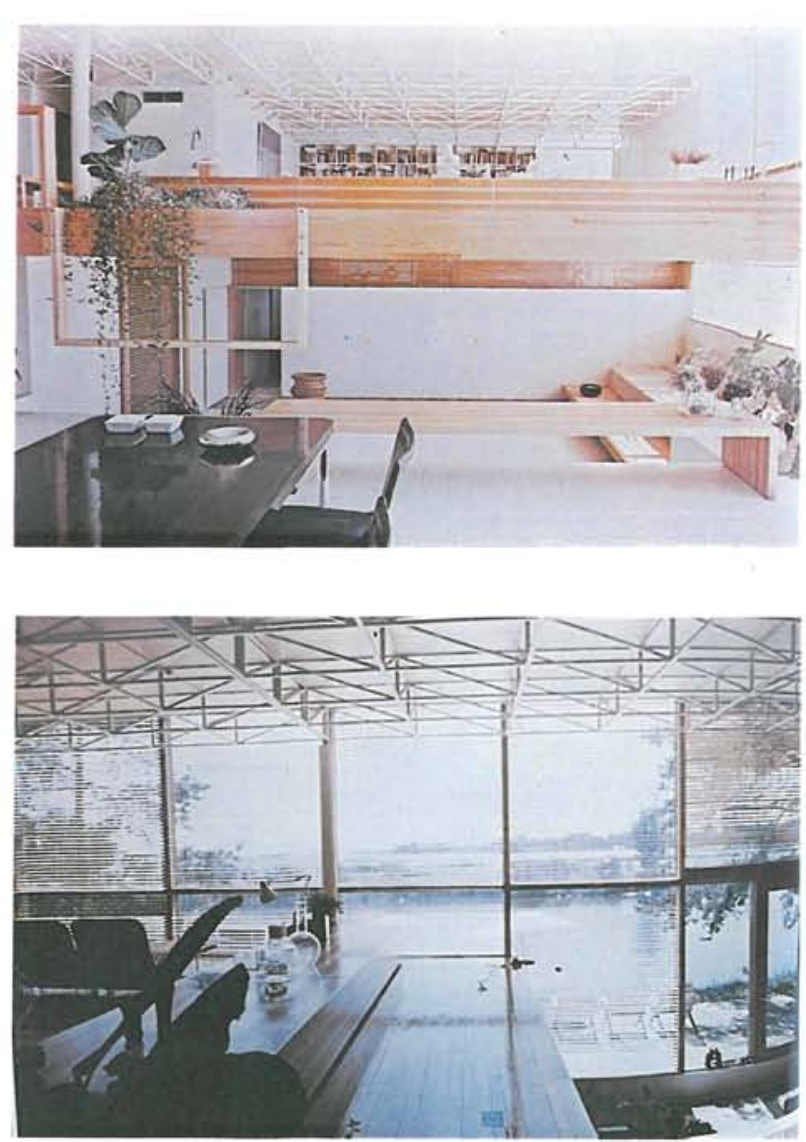
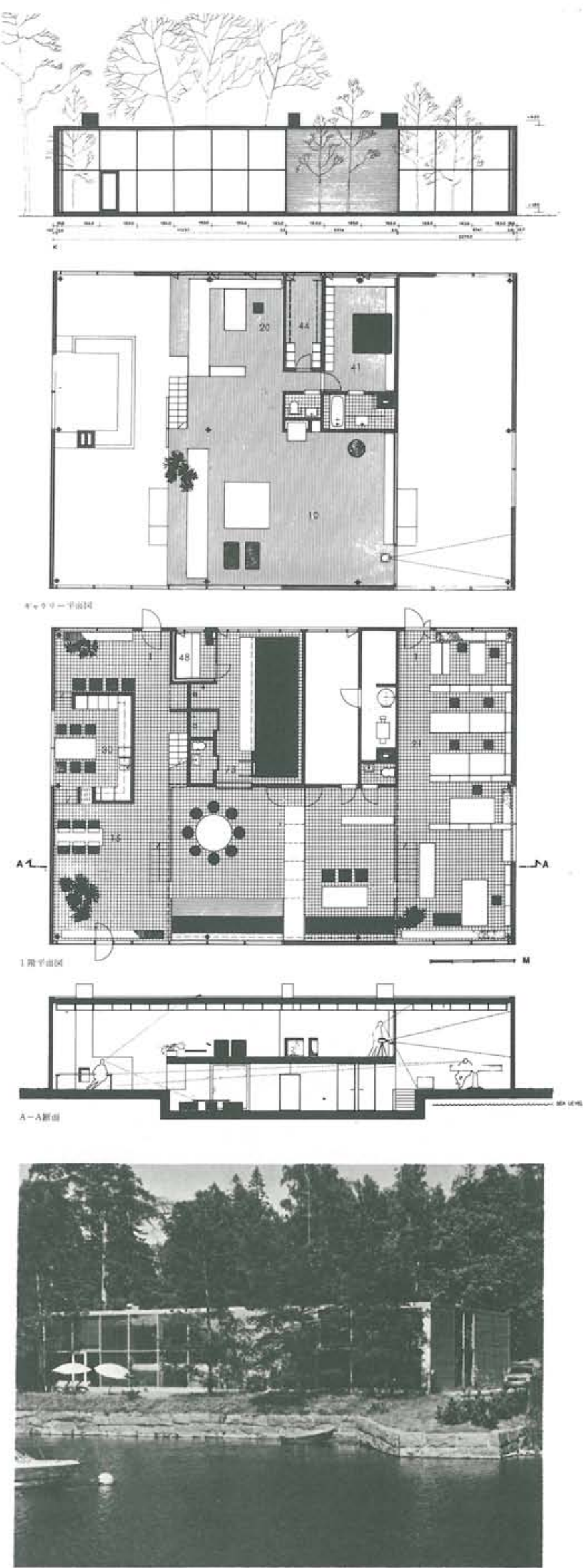


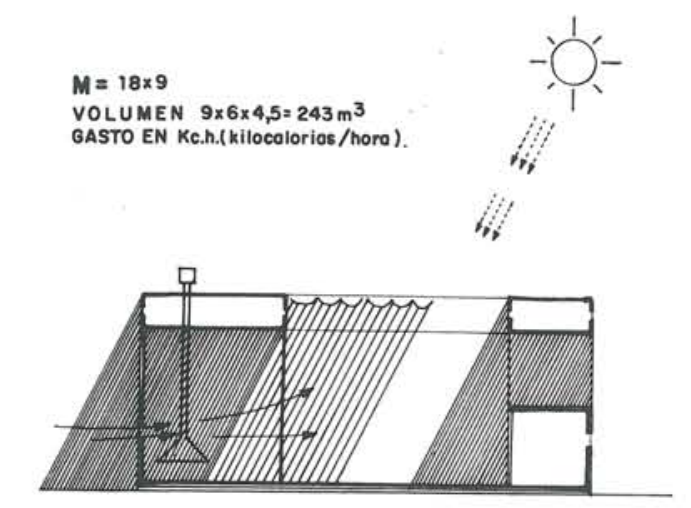

DIA

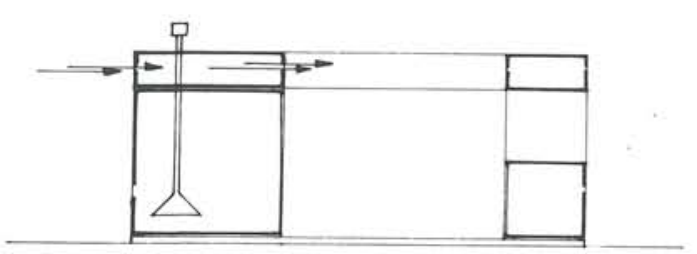

NOCHE
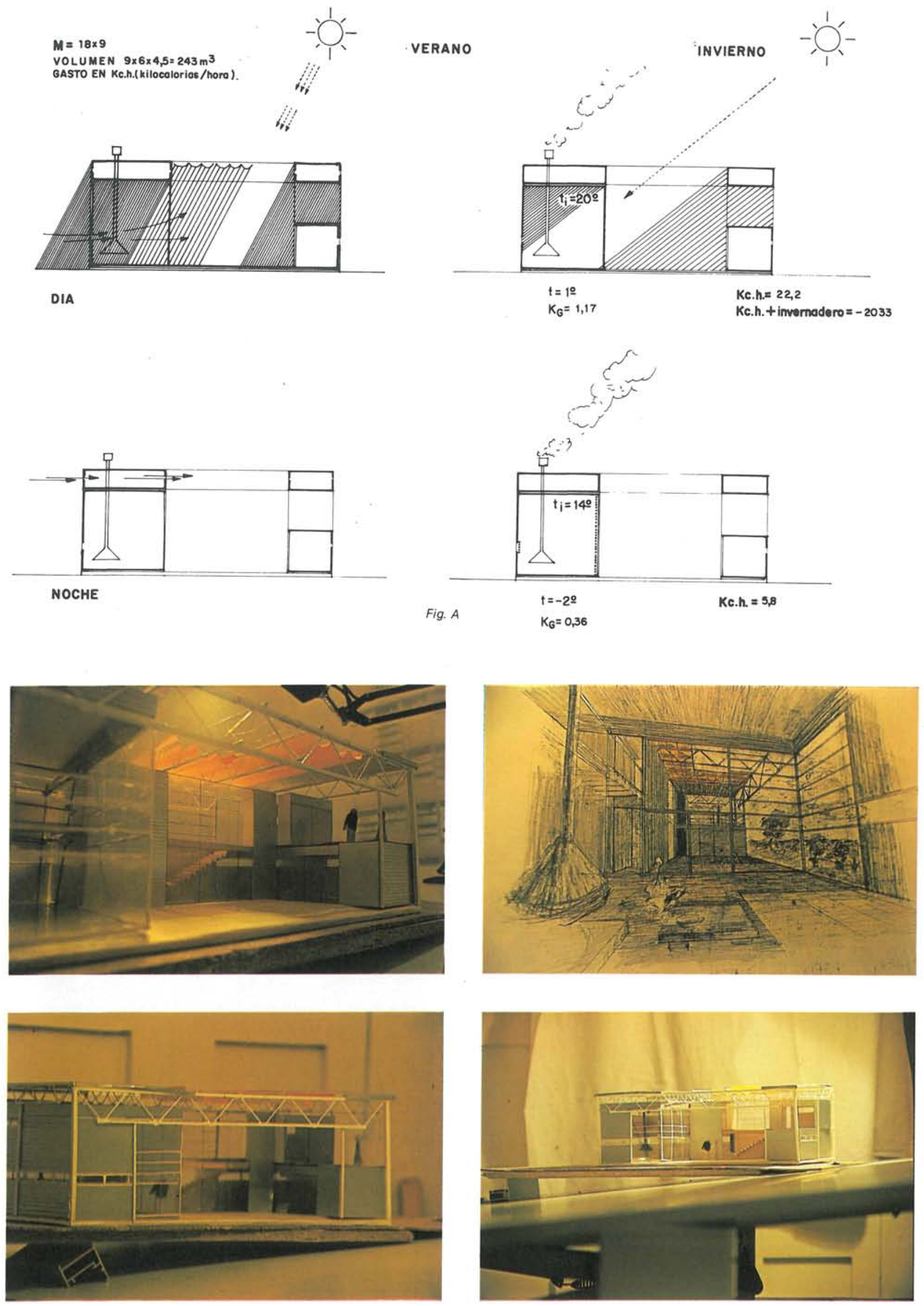

http://informesdelaconstruccion.revistas.csic.es 
LA CASA H.I.T. (Habitación Industrial Trasformable, Madrid, 1985)

Arquitecto: J. Miguel Reyes

La casa H.I.T. se desarrolla en dos alturas y puede ocupar de 212 a $122 \mathrm{~m}^{2}$ útiles, según la normativa actual del Ministerio de la Vivienda.

\section{Componentes constructivos}

Está construida a partir de dos clases de componentes: "el soporte" (constituido por una estructura metálica estándar de nave industrial, con sus acometidas de instalaciones) y las "unidades separables".

Para la estructura metálica se parte de la utilización de un módulo estándar de edificación, que cubre una superficie de $9 \times 18 \mathrm{~m}$, y cuya solera viene incluida en el montaje (Págs. 12 y 13). Así mismo se le puede aplicar indiferentemente un cerramiento de panel sandwich y una cubierta deck, donde la organización modular de la estructura permite un apoyo constructivo, tanto horizontal como vertical. La situación y colocación de huecos vendrá dada en función de este despiece previo.

El montaje y, por tanto, el funcionamiento estructural y constructivo queda garantizado por el fabricante (comportamiento) hiperestático de la estructura, acabados, características físicas de los materiales, fijación y estanquidad de las juntas).

Las unidades separables (estructura interior y particiones) son a base de mecanotubo y paneles de aglomerado, con procedimientos de fijación patentados o mobiliario.

El 2. ${ }^{\circ}$ nivel de altura se forja con paneles de aglomerado y rastreles o chapa rizada y se pavimenta con moqueta, goma o barniz. Los conductos e instalaciones son aéreos, preferentemente flexibles.

\section{Esquema de organización}

Alberga un programa convencional de vivienda: estar-comedor, cocina con antecocina, de dos a cinco habitaciones, con un aseo y un baño. Para su distribución se tuvieron en cuenta los típicos parámetros dados por la situación en la parcela:

- Orientación: Máxima apertura al sur y mínima al norte.

- Acceso: La casa se privatiza en la vertiente de acceso y se abre en la opuesta.

- Vistas: Vistas deseables hacia el suroeste.

Con tales requisitos y las pautas formales de los componentes constructivos elegidos, la casa se conforma según bandas de uso paralelas a lo largo de la edificación y divisiones perpendiculares a éstas.
III

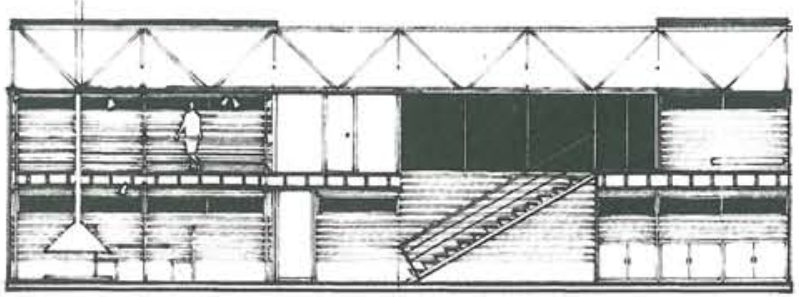

Sección longitudinal

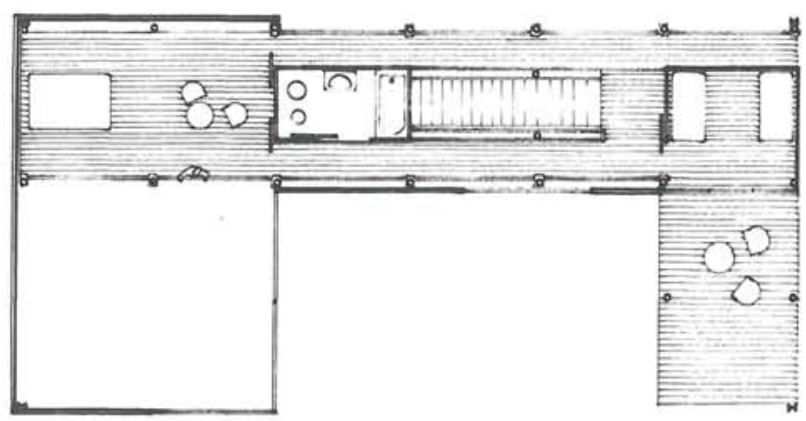

Planta alta
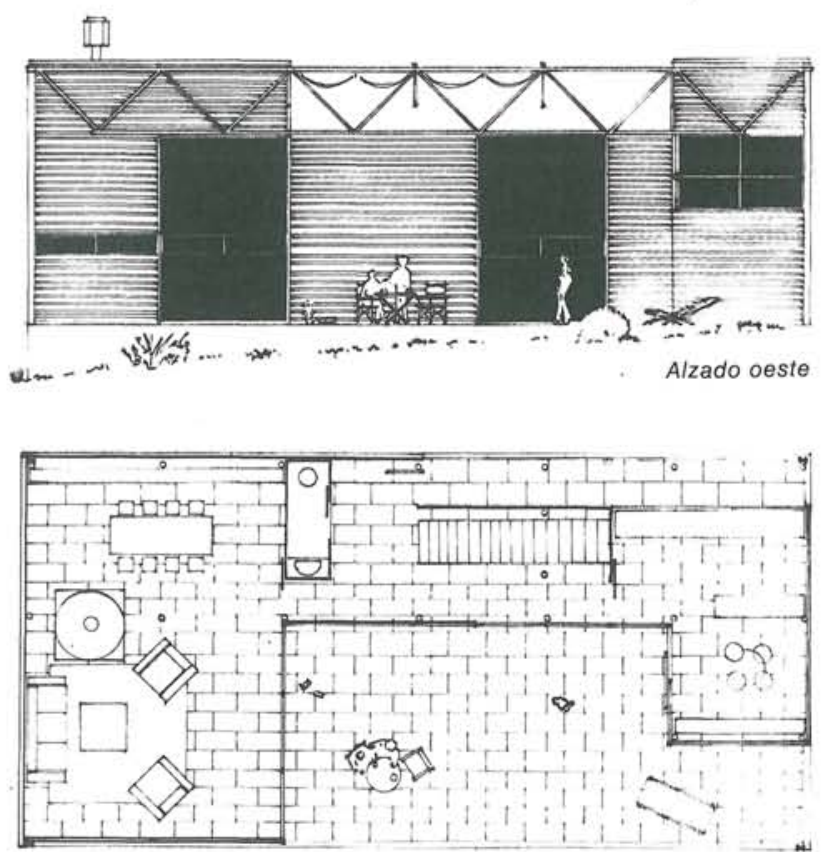

Planta baja

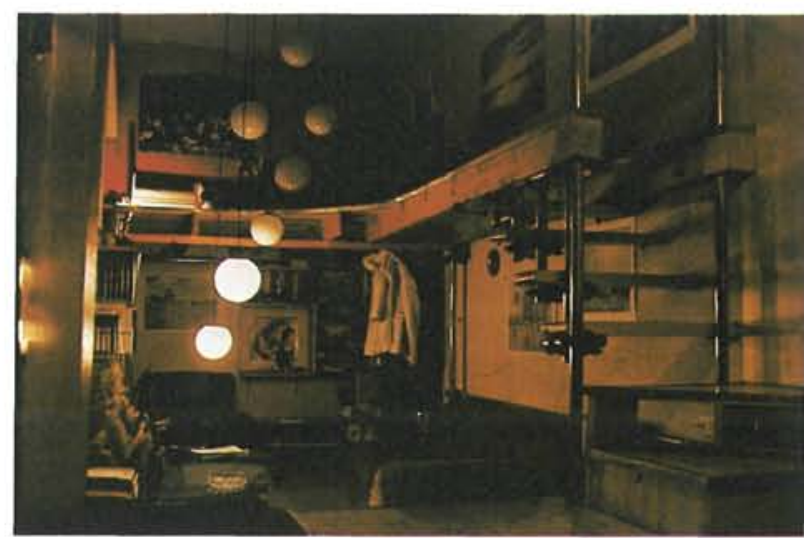


Las bandas serán dos: una de doble anchura que la otra (Fig. B). En la estrecha se sitúa preferentemente la $2 .^{\text {a }}$ altura y es denominada «banda de lo necesario" (aseos, cocina, entrada, escalera, habitaciones individuales, comedor). La doble, por el contrario, contiene preferentemente las dobles alturas, y es denominada "banda de lo complementario» (estar, porche, terrazas, despensa-lavadero, trastero).

La colocación relativa de estas bandas y su tratamiento en fachada favorecen la típica relación delante-detrás con respecto a la condición de acceso. Especializando y densificando mucho la «banda necesaria» (que separa las dos vertientes), frente a la "banda complementaria», que goza de mayor libertad espacial.

Por otra parte, se dispone en la edificación de un número de divisiones perpendiculares a las bandas anteriores que vienen dadas por el propio orden de la construcción y la estructura elegida (Fig. B). Con estas divisiones se modulan los usos y sus agrupaciones, de forma que, para cumplir los requisitos de vistas y orientación, la casa queda dividida en dos alas. Una de éstas es el doble de la otra, en función de la propia ocupación de los usos: estar-comedor, habitaciones grandes, en la "doble» y cocina, lavadero, habitaciones pequeñas en "la sencilla».

Entre ambas queda un porche que, dando forma a la casa, permite la apertura del ala principal al sur a la vez que al suroeste, para las vistas y orientación solar, mientras que el "ala sencilla» continúa manteniendo el grado de privacidad de la «banda complementaria» (a la que vuelca la casa según la condición de acceso).

\section{Comportamiento bioclimático (Fig. A)}

La casa está orientada de forma que en invierno, durante el día, recoja el máximo de calorías mediante el efecto invernadero provocado a través de una importante superficie acristalada $\left(30 \mathrm{~m}^{2}\right)$ en la fachada del "ala doble» con orientación suroeste. Esto que, durante la noche, supondría una importante pérdida de calorías, se neutraliza mediante la colocación de cortinas de tejido denso que, al dejar cámara de aire entre sus pliegues y el cristal, disminuyen mucho el $\mathrm{K}_{\mathrm{G}}$, sin necesidad de "climatit», cosa que favorece el comportamiento térmico del paramento.

Así se retiene el calor acumulado en la solera durante el día mediante el efecto invernadero. A la vez, en el flanco más desfavorable del ala (el norte), se sitúa la chimenea que, con sus rescoldos e inercia térmica, colabora a mantener la temperatura ambiente deseada. En el «ala sencilla», esta labor de calentamiento nocturno es confiada a la influencia de la cocina sobre las estancias que se encuentran encima de la misma.
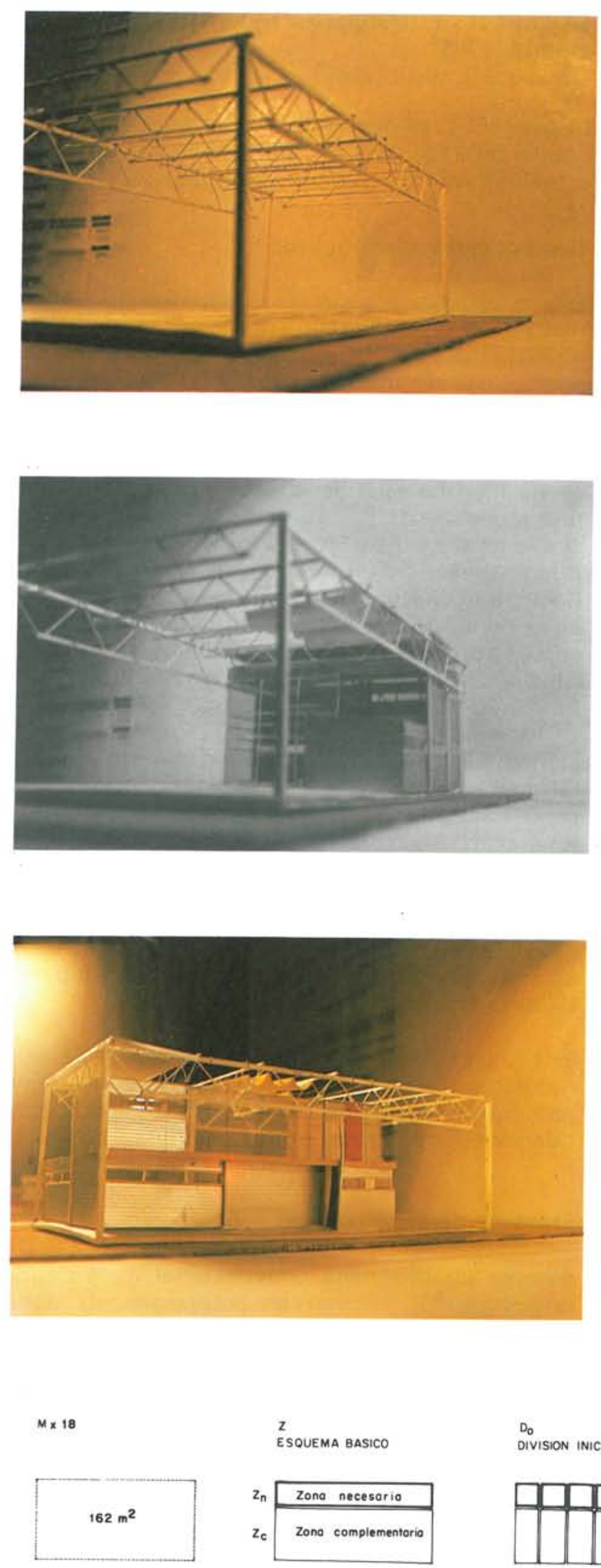

$D_{0}$ DIVISION INICIAL

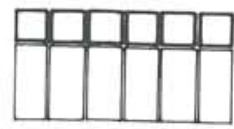



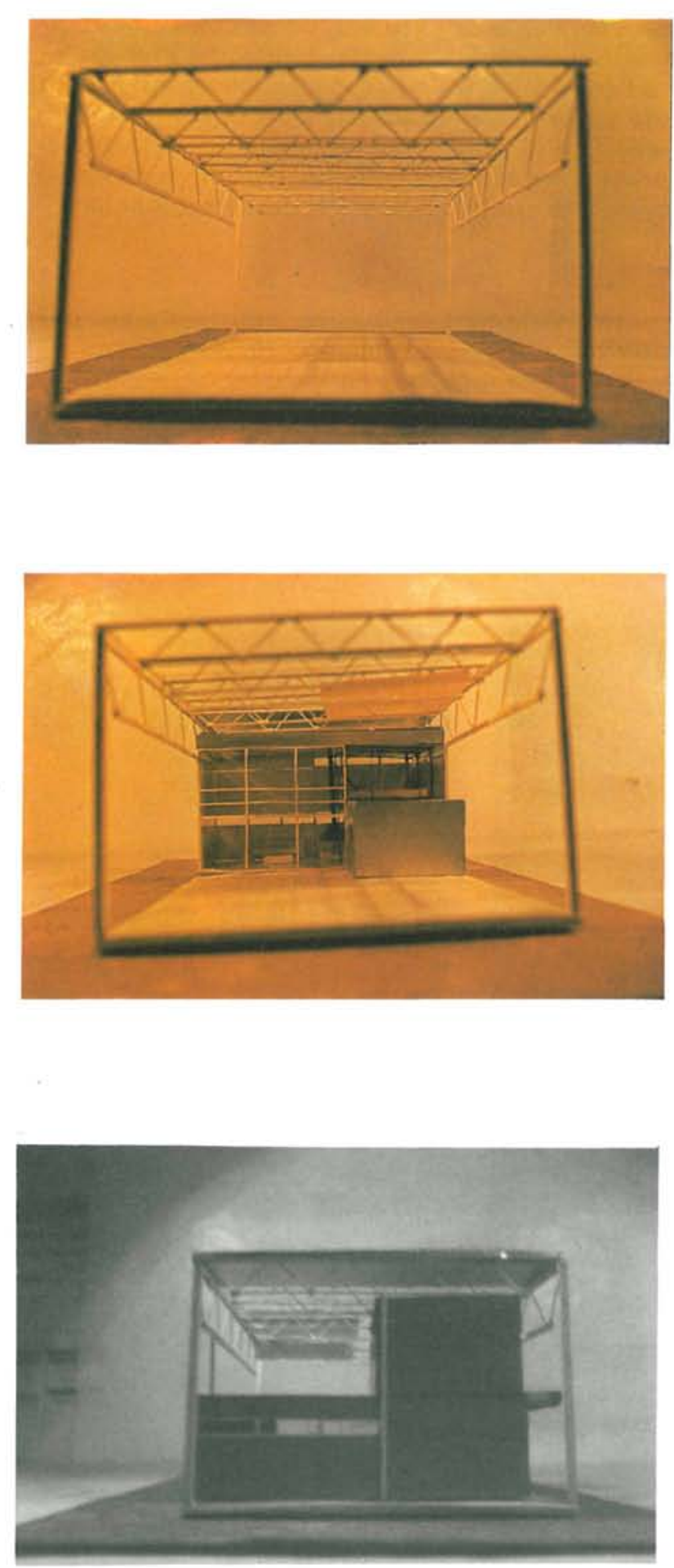

$D_{6}$ ISTRIBUCION PROPUESTA

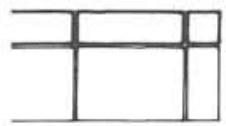

D.

$\begin{array}{ll}D_{1} & D_{2} \\ \text { CON I DIVISION + SERVICIOS } & \text { CON } 2 \text { OIVISIONES+SERVIIOOS }\end{array}$

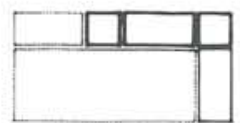

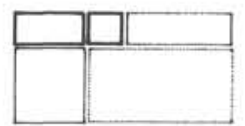

En verano, durante el día, el efecto invernadero que perjudicaría el acondicionamiento del ala doble, se modifica mediante la colocación de toldos en el porche y provocandó una ventilación cruzada de abajo a arriba en la estancia, creándose una zona en sombra de protección entorno a la misma.

Durante la noche, una ventilación forzada, a través de una cámara practicable prevista en cubierta, refrigera el ambiente.

Para la fachada oeste se cuenta con la típica cortina vegetal de hoja caduca, a la altura y distancia deseadas.

\section{Confort (habitabilidad)}

Uno de los principales componentes del confort, el acondicionamiento climático, ya ha sido examinado.

Otro, el del aspecto general: calidad material, acabados, cualidad espacial, iluminación, color, queda referido al resto de los prototipos aquí presentados.

Y en último lugar, señalar cómo en esa relación con el entorno, tanto visual como climática, los aseos y habitaciones quedan abiertos a poniente y al amanecer, en dos grados distintos y de correspondencia.

\section{Gestión y desarrollo}

El interés fundamental de la HIT estriba en la clase de gestión que plantea su construcción. Dentro de la misma línea de los prototipos que se han expuesto hasta el momento, trata de eliminar intermediarios entre el fabricante de los componentes y el usuario, de forma que el montaje de los mismos se realiza por el propio fabricante - contratado por el usuario-o puede ser colocado y manipulado fácilmente por el mismo usuario, lo que supone un importante abaratamiento de la construcción.

En el momento de su proyecto, el coste de la HIT era de 3,5 millones de pts.: $22.000 \mathrm{pts} . / \mathrm{m}^{2}$ que, en correspondencia con otra vivienda de sus mismas características espaciales en el mercado convencional, sería de $35.000 \mathrm{pts} . / \mathrm{m}^{2}: 7_{1}$ millones de pesetas.
DOL LAS $Z_{n}$

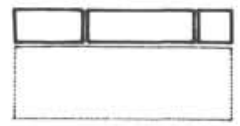

$\mathrm{D}_{6}+1$

DESARPOLLOS DE CRECIMIENTO $\quad D_{6}+D_{6}$

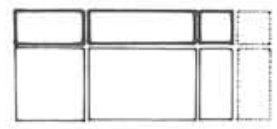

$\mathrm{O}_{6}+2$

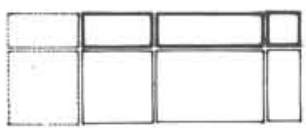

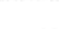

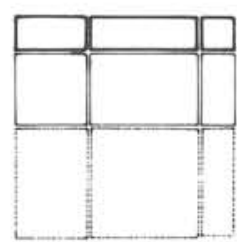


Aparte de esto, la posibilidad de gestión directa por parte del usuario a partir de unas pautas formales dadas por los propios componentes facilita el desarrollo parcial o por fases de la construcción, apareciendo ésta siempre como un elemento acabado y evitándose los típicos problemas administrativos de la autoconstrucción: presupuestos y legislación. Se exponen aquí siete posibles fases de ejecución de la vivienda (Págs. 12 y 13).

\section{Agrupación}

También son importantes las posibilidades de agrupación, aunque quizá para ello sería preciso efectuar algunas modificaciones al H.I.T., justamente por depender tales modificaciones del tipo de agrupa- ción. Este depende, a su vez, de las condiciones urbanas del asentamiento, ello conduciría a una prolijidad de variaciones que son justamente las que, en cada caso, determinarian la distribución u orden general de la propuesta. No obstante, a continuación se presenta un ejemplo real de agrupación que servirá como verificación de tal posibilidad.

El "EH» (Sistema construttivo industrializzato per abitazioni a tipología evolutiva) 1978-82 Arquitecto: Renzo Piano

Se encuentra en Perugia y ha sido gestionado con la participación del usuario para la "Communa de Corciano», por Vibrocemento Perugia S.P.A.
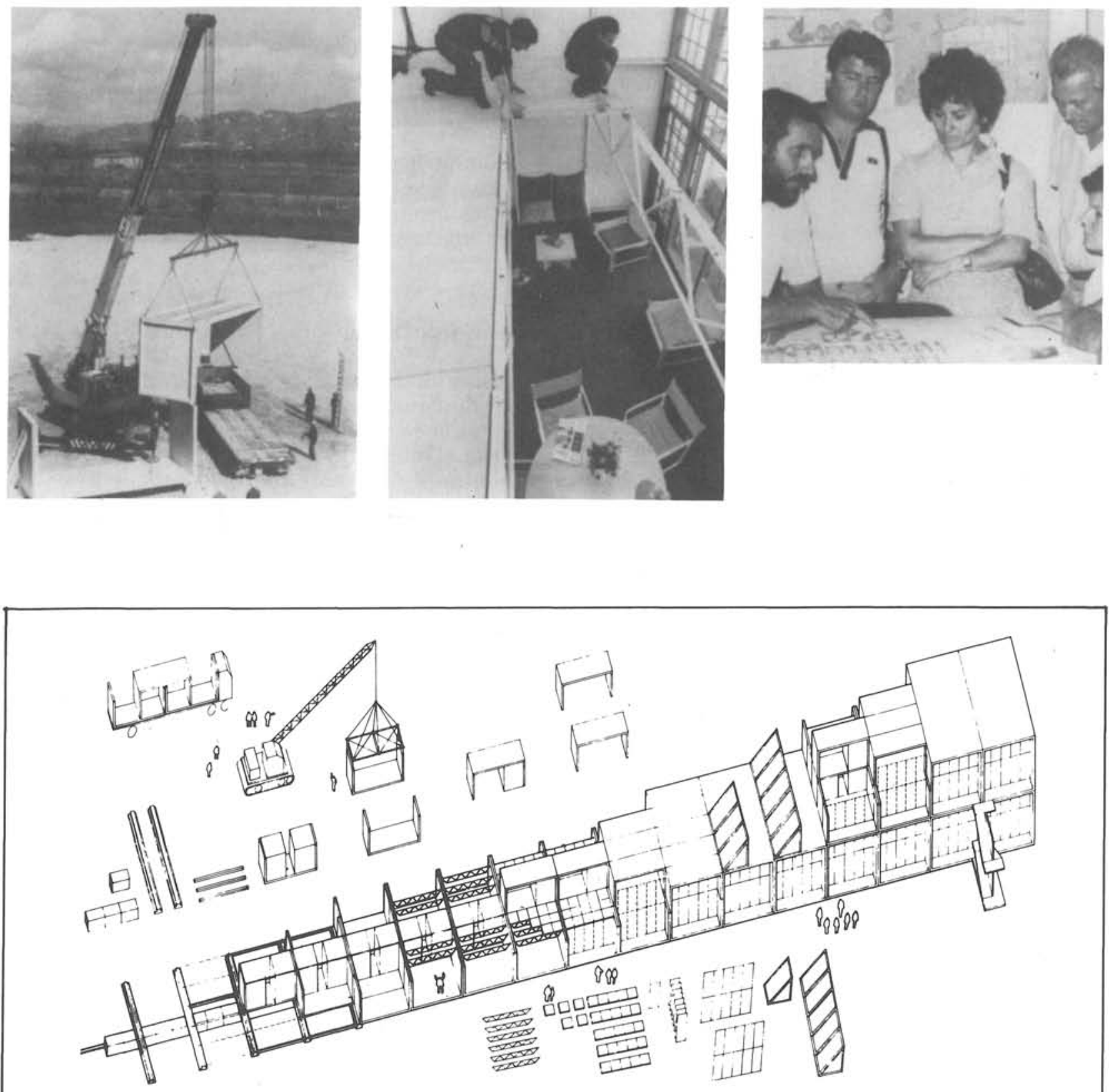
Se trata de una agrupación de viviendas cuya extensión oscila entre 50 a $120 \mathrm{~m}^{2}$ y que llega a generar un medio urbano. La vivienda se ha planteado compuesta, por una parte, de un soporte técnico y estructural fijo con sus propias leyes de desarrollo $y$, por otra, de un espacio tanto exterior como interior que el propio usuario puede manipular directamente.

Se puede confirmar nuevamente la existencia de estas reglas de juego $u$ órdenes formales de distribución, que permiten operaciones compatibles de flexibilización espacial de unos componentes ligeros que el propio usuario maneja y otros fijos que monta el propio fabricante.

También, a través de esta actuación, se dispone de una buena muestra de cómo el usuario, en régimen de participación, decide y gestiona su entorno en asentamientos actuales de media densidad.

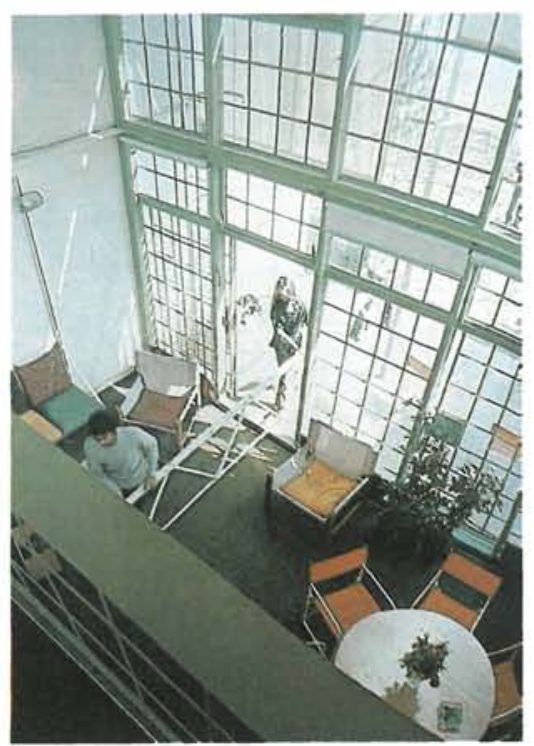

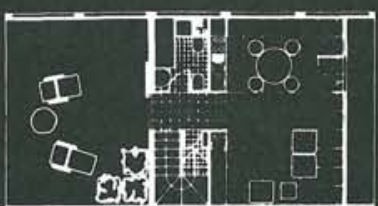
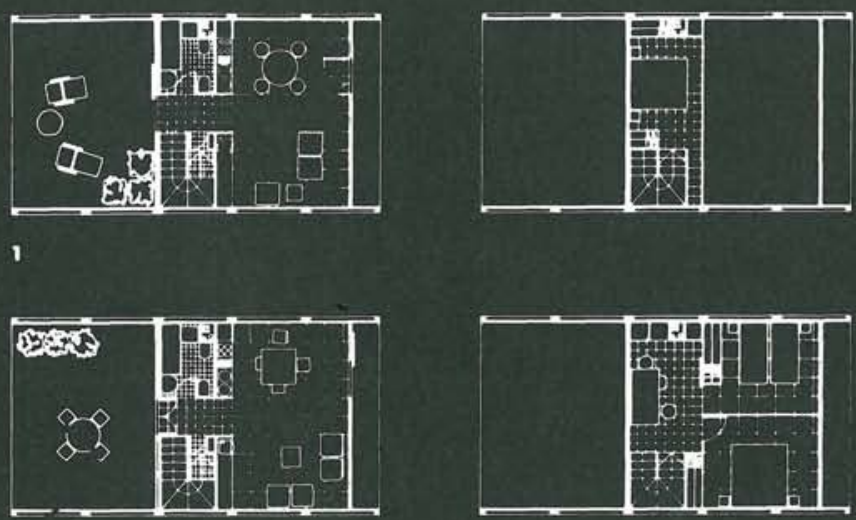

2
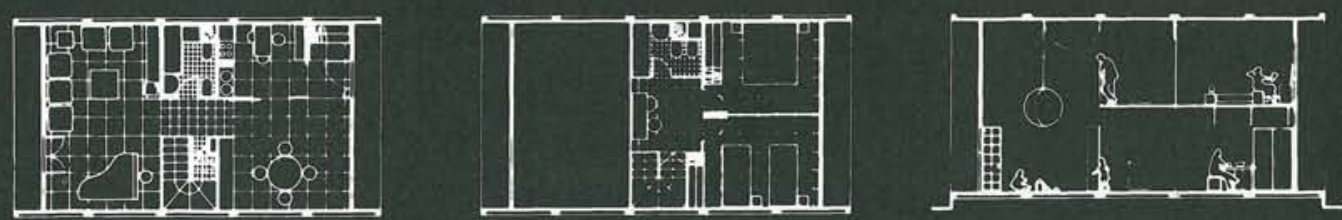

3
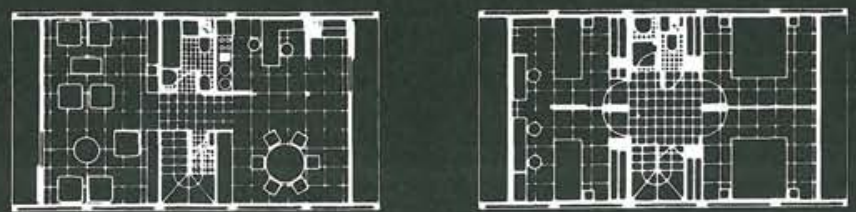
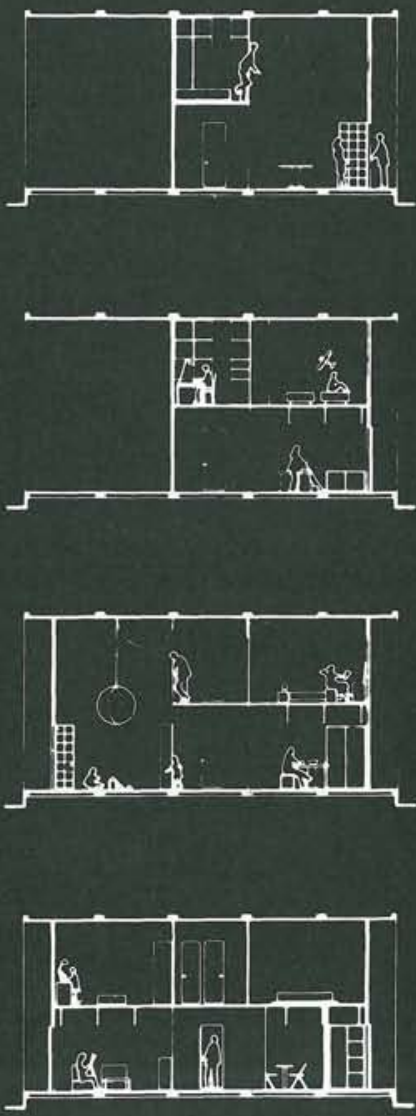


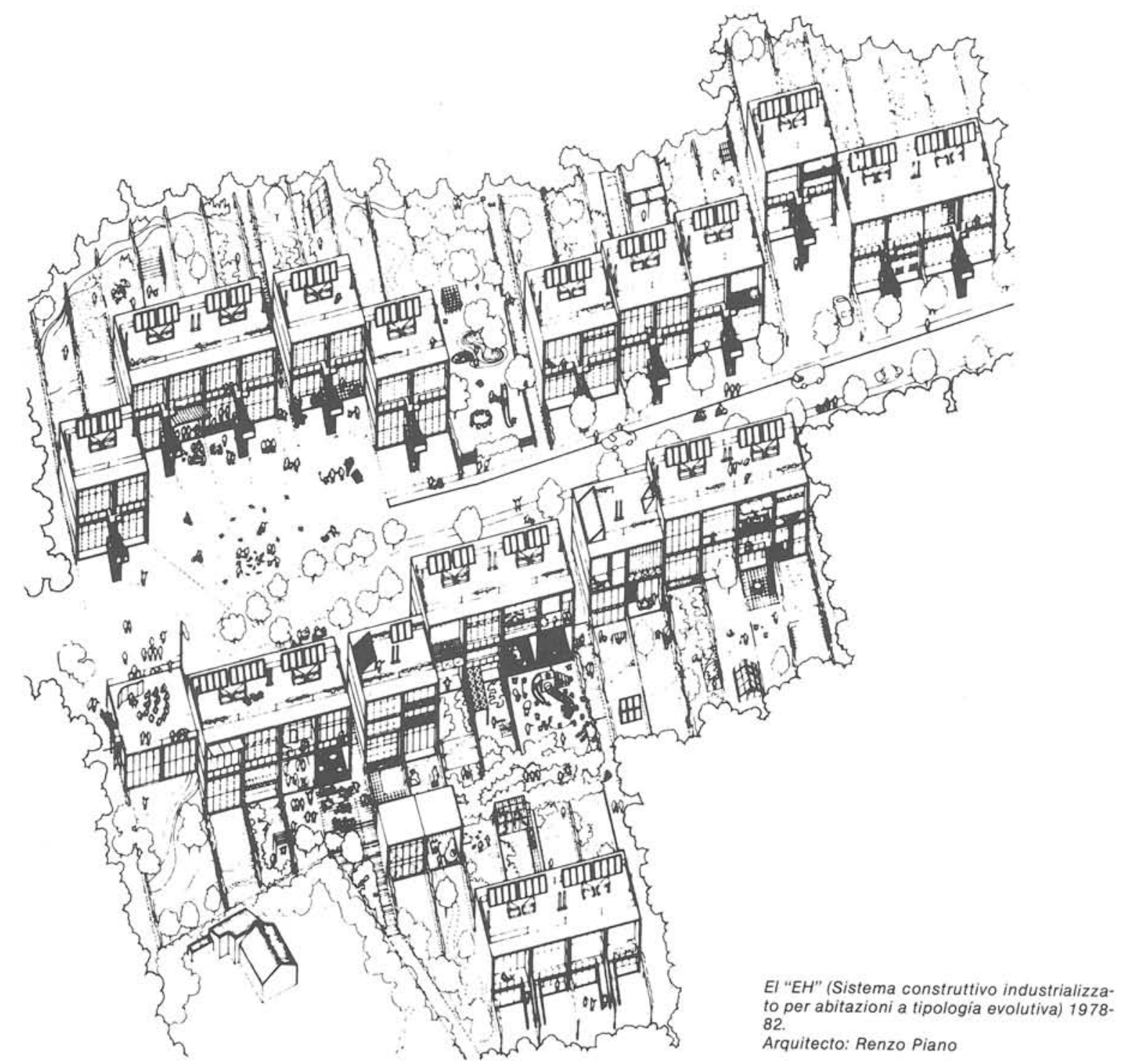

\section{UNA DIFERENCIA}

Llegados a este punto, cabe hacer el examen de causas y motivos por los cuales, sin embargo, lo que generalmente aparece en el mercado asociado a la "construcción ligera» o a la «prefabricación abierta» tiene otros caracteres y resultados (Pág. 17). Es decir: ¿por qué la construcción por componentes compatibles no ha encontrado aún el reconocimiento de un campo propio de desarrollo?

En principio, son los consabidos «impedimentos e inconvenientes sociales", glosados y reconocidos por todos a la hora de hacer compatible el inseparable binomio que caracteriza a una civilización: "tecnología-cultura».

Ahora bien, ¿̇con qué nos encontramos al hacer un análisis de la construcción por componentes compatibles desde tales «impedimentos e inconvenientes», análisis realizado no ya sobre los planteamientos y manifiestos utópicos de los 60 y sus «megaestructuras tecnológicas», sino sobre hechos patentes y realizados, al alcance de cualquiera?
¿Qué condiciones proponen? o ¿cuáles les son impuestas desde la sociedad?

\section{UNA METODOLOGIA}

Generalmente, en los círculos dedicados a la construcción prefabricada, siempre se ha asociado la idea de modulación a la de prefabricación, como si cumpliendo solamente con este requisito bastase ya para poder hablar de resultados arquitectónicos óptimos y deseables: nada más lejos de la realidad.

Cualquiera que se acerque al hecho arquitectónico con un ánimo no sólo "esteticista» y superficial o, por el contrario, totalmente mercantilista, encuentra inmediatamente cómo la aparente complejidad de las partes, tanto espaciales como constructivas, responde a una "ley general» u "orden» que sirve para categorizar, ensamblar o incluir unas piezas con otras, o en otras, y disponer así de una base operativa. 
La generación o uso de estos órdenes vendrá definida por la metodología utilizada en cada caso. En general, se responde a ciertas tipologías y a su uso.

En el caso que nos ocupa: la vivienda y su agrupación (asentamientos residenciales), es sobradamente conocido el repertorio tipológico estándar de habitación desde que, a principios del siglo XX, "el Racionalismo Internacional» y sus CIAM analizaron y determinaron exhaustivamente el tema. Esto, sin embargo, se hizo sólo desde planteamientos estáticos de la agrupación, lo cual dio lugar más a la definición de modelos fijos que de tipos (que siempre admitirán variaciones y cambios reales).

Pocos han sido los estudios realizados desde tales planteamientos dinámicos. Estudios que, con tal base de partida, se ven obligados a tener que hacer un mejor análisis abstracto del orden que plantean: cuáles son sus elementos y cuáles sus operaciones posibles (sin poder apartarse en ningún momento de su formalización). Esto implica la definición de componentes y su compatibilidad, motivo que nos hace dirigir la atención sobre dos importantes y destacados ejemplos.

El primero de ellos fue definido por el SAR (Stiching Architecten Research), grupo dirigido por J. Habraken. El interés de la normativa propuesta por el SAR (Ed. Holanda, 1965; España, 1979, bajo el titulo: «el diseño de soportes»), estriba en que automatiza los criterios de decisión a partir de la codificación espacial de la vivienda en función de su agrupación y no sólo conceptualmente, sino también formalmente.
Esta codificación está planteada para poder operar con el asentamiento como agrupación dinámica y no estática, lo cual se dijo anteriormente.

Se definen los conceptos de "soporte». y «unidad separable», así como los de "bandas», «márgenes», "divisiones» y "usos». Todos ellos, conceptos típicos de orden y categoría, dentro de una organización arquitectónica del espacio (Pág. 18). Sus tablas de relaciones nos dan las clases de operaciones y compatibilidad para los mismos. Paralelamente a esta publicación, se llevaba a cabo por Jossic, Candilis \& Woods (acérrimos continuadores de la teoría Corbuseriana del Modulor) la realización de la "Free University of Berlin» (1965), siguiendo parecidos planteamientos. Las leyes de compatibilidad están relacionadas esta vez directamente con "la teoría de la proporción», dejando de hacerlo estáticamente (a la manera clásica) para pasar a hacerlo dinámicamente.

Esto, que hace aparecer el resultado como algo aparentemente intrincado y complicado de desentrañar o, por el contrario, sumamente vano o aleatorio, por responder sólo a una ley superficial de modulación, no es, por el contrario, ninguna de ambas cosas.

En los esquemas de organización y distribución realizados en el EDAAC $\left(^{*}\right)$ se expresa la ley establecia por el proyectista (Pág. 19).

Con estas codificaciones y campo espacial de operaciones se dispone de unos programas de trabajo que hacen la toma de decisiones automática, facilitándose incluso la gestión de los mismos.

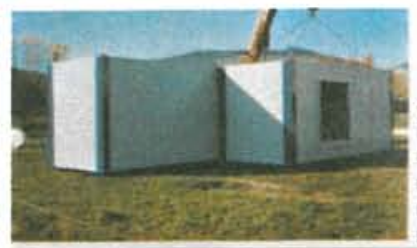

GRAN AISLAMIENTO SOLQYENT PARFATI LIGERAS WEGERES

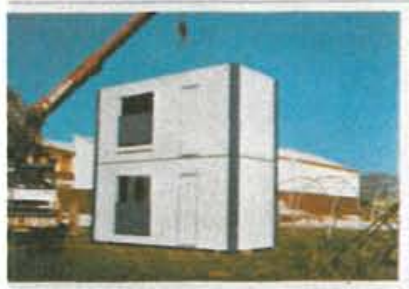

UN SISTEMA DE CONSTRUCCION N SISTEMA DE CONSTRUCCION
CON MULTIPLES APLICACIONES

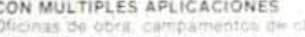
se lenas cambings itc oth

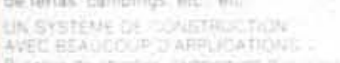

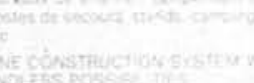

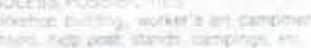

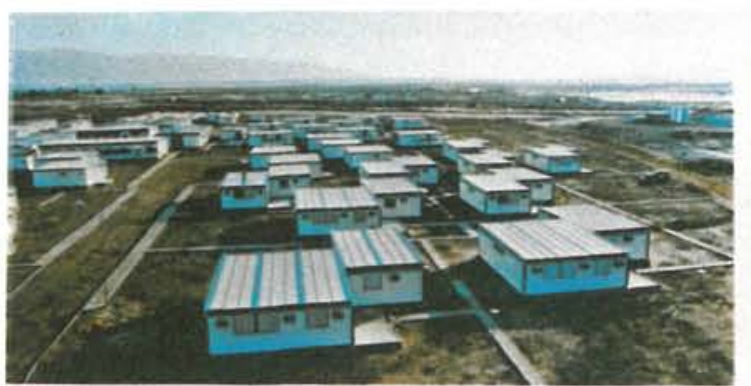

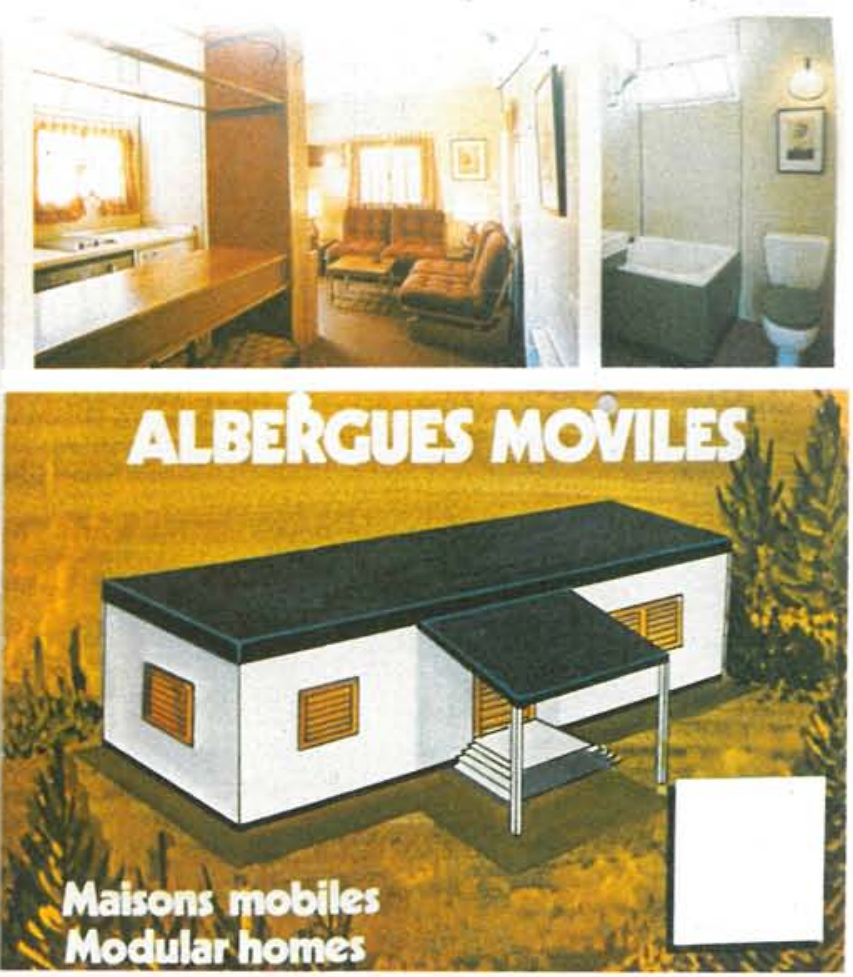



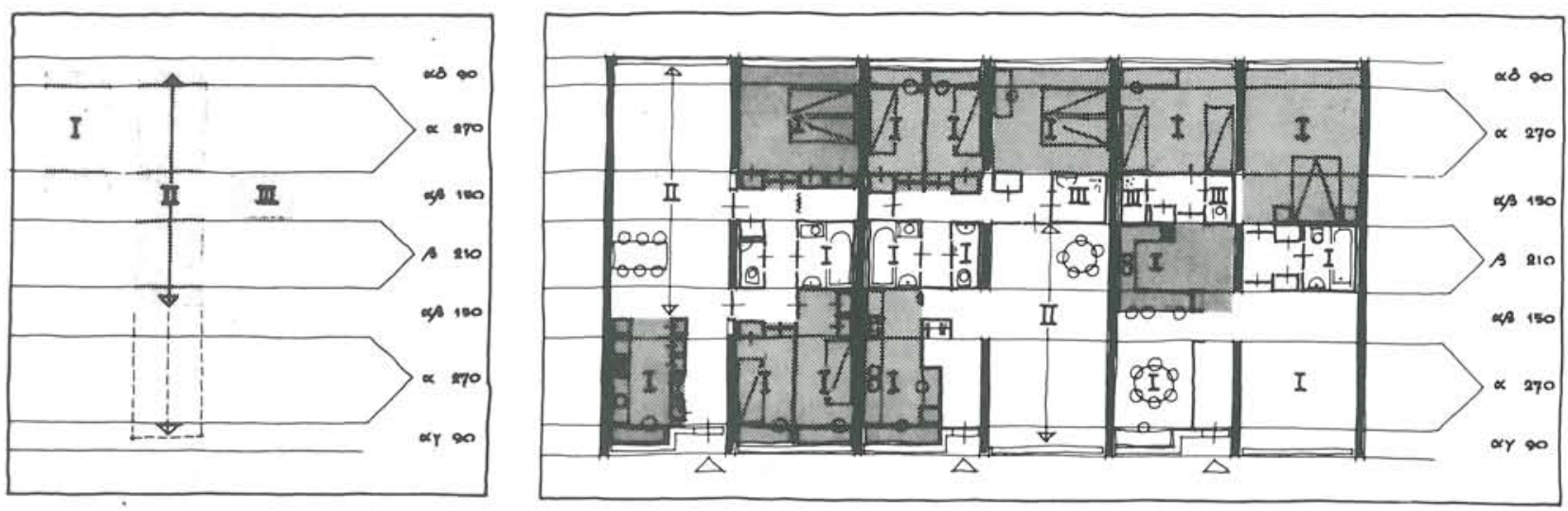

ESTE PROGRAMA OPERA CON LA NOTACION Y UNIDADES DE LA FIG. EN PANTALLA

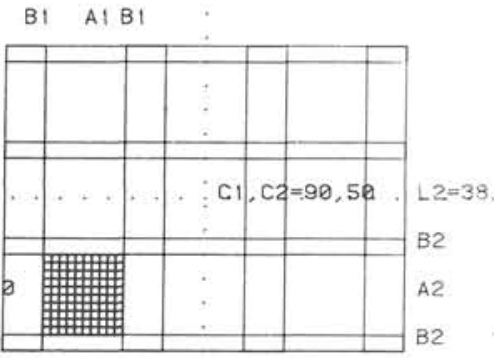

105

$$
\therefore 1=50
$$

campo con3 divisiones

en $L i: 3 D I=3 A$

$r^{3}$ divisiones en $L 2: 3 D 2=3 A 2$

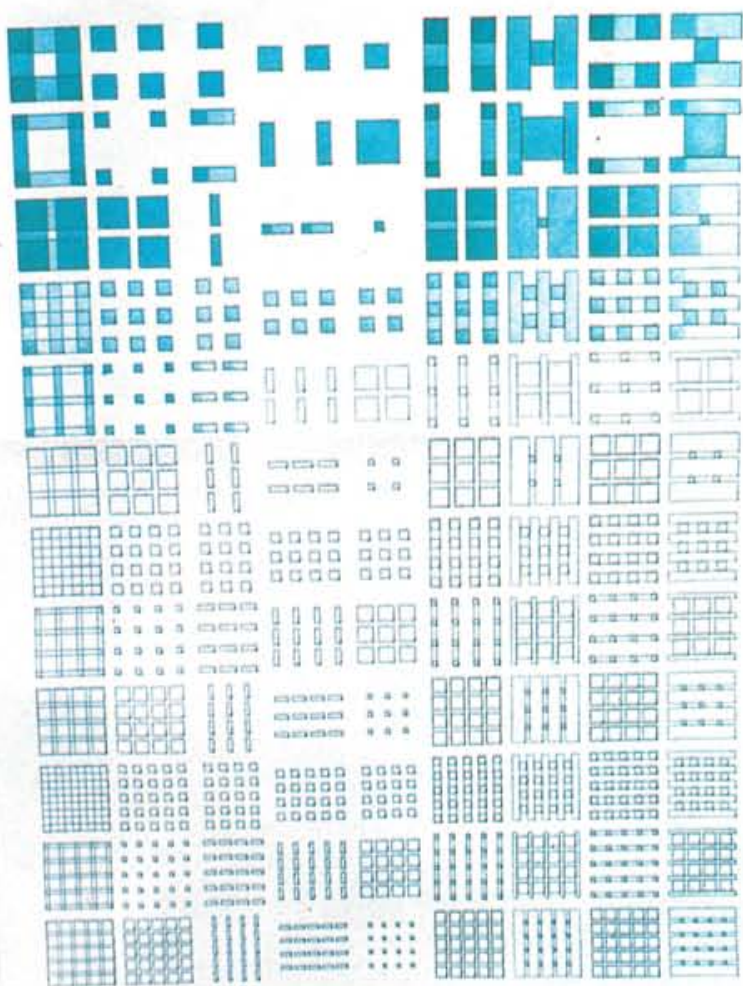

EI TYR programa para operar con tramas Tartán y Retículas, realizado en el EDAAC.
Todo esto, aparentemente obvio una vez expuesto, no es lo que se reconoce, sin embargo, desde la industria, ni desde el estamento docente.

En las Escuelas Oficiales «al uso» sí se enseña a discernir sobre el valor del "orden en arquitectura» (la consabida: "relación de las partes con el todo»), y a recurrir a un bagaje de casos y tipologías conocidas, pero siempre de forma académica, es decir, clásica, acudiendo siempre a «rigurosos» órdenes, que podríamos llamar "cerrados» frente a los «abiertos» aquí citados. Estos últimos quedan siempre desestimados frente a aquéllos, dada la aparente frivolidad o falta de criterio cara a una «importante y rigurosa calificación», cuando bien podrían formar parte de una especialización en la que las tipologías automáticas tomasen su propia naturaleza cibernética, dejando de ser así «mal entendidos» modelos estáticos y liberando, por otra parte, a otros procedimientos proyectuales de tal «automatismo disciplinar».

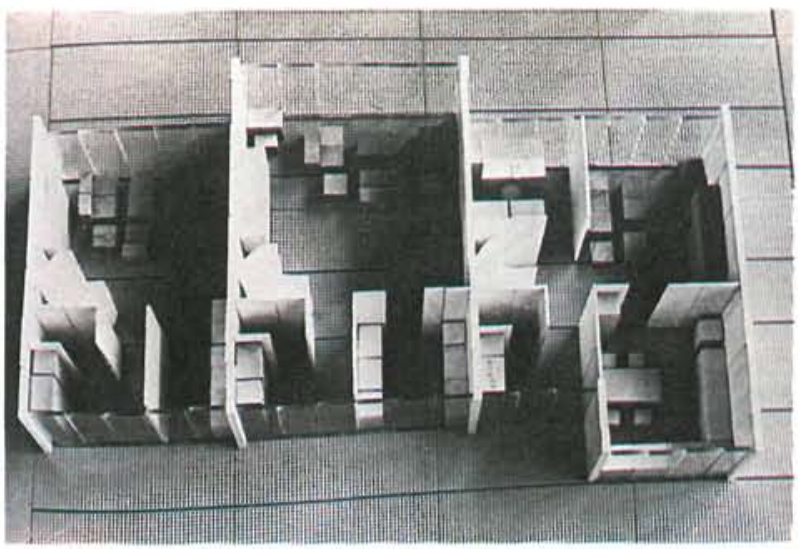

(*) EI EDAAC (Equipo de diseño Arquitectónico Asistido por Computador), adscrito como seminario al Departamento de Análisis de Formas, dirigido por Javier Seguí de la Riva, de la Escuela Técnica Superior de Arquitectura de Madrid, es, en la actualidad, el continuador de los trabajos que en los 60 se realizaron en el Centro de Cálculo de la Universidad Politécnica de Madrid y que dieron lugar a estudios como «Un Modelo Procesativo de Diseño», o el «programa GEN», importantes antecedentes teóricos de todo lo anterior. 
Esta clase de metodologías cibernéticas de comportamiento espacial, aparentemente tediosas y prolijas en su definición son, sin embargo, fácilmente controlables, si tal control se efectúa con sus herramientas propias. Sólo basta mecanizar a través de un ordenador tales programas ya automáticos en su concepción. Esto, que no parece nada nuevo en el terreno del CADCAM o el C.D., sin embargo lo es, ya que los programas comerciales en este campo resuelven problemas bien eminentemente gráficos (geometría analítica y descriptiva), bien de cálculo (sistemas muy determinados de ingeniería), pero nunca de geometría en relación a cuestiones de orden, grado o categoría. Para ilustrar tal posibilidad, citamos el TYR (Programa para operar con tramos Tartán y Retículas), también realizado en el EDAAC (Pág. 18), el cual, una vez introducida en máquina la información formal del campo geométrico definido, efectúa operaciones de separación y distribución de los órdenes topológicos definidos por el propio sistema, cualificados en forma abstracta.

De este modo, la industria, al no disponer de técnicos cualificados, continúa confundiendo «los tipos» con "los modelos» y «la variación» con «la permutación», conformándose con seguir modulando correctamente al no tener ni interés, ni noticias de que las cosas puedan ser de otra manera, mientras una lluvia incesante de componentes pertenecientes a un «riguroso y paradójico infinito-orden cerrado» continúan invadiéndonos interminablemente.

\section{UNA TECNOLOGIA}

A la vista está, tras los ejemplos expuestos anteriormente, que, tecnológicamente, el hecho de la construcción por componentes compatibles es posible e incluso da respuesta a agrupaciones de habitación en altura.

He aquí dos ejemplos de ello:

El primero se encuentra en Suiza (Fig. 6) y el segundo en Bruselas (1974-76) (Fig. 8). Ambos utilizan ya para este caso estructura portante de hormigón armado.

Mientras el primero, como los anteriores elige, dentro de la prefabricación abierta, los componentes con qué actuar previamente y con éstos desarrolla la edificación; el segundo, por el contrario, admite una gran gama de materiales y posibilidades, dado que los criterios de orden arquitectónico del segundo son sólo de coordinación dimensional. Este adopta los convenios del SAR, típicos para la prefabricación abierta el primero, fija además criterios de compatibilidad espacial, criterios que como hemos visto anteriormente, también se definen en el SAR, pero en un nivel distinto del material.
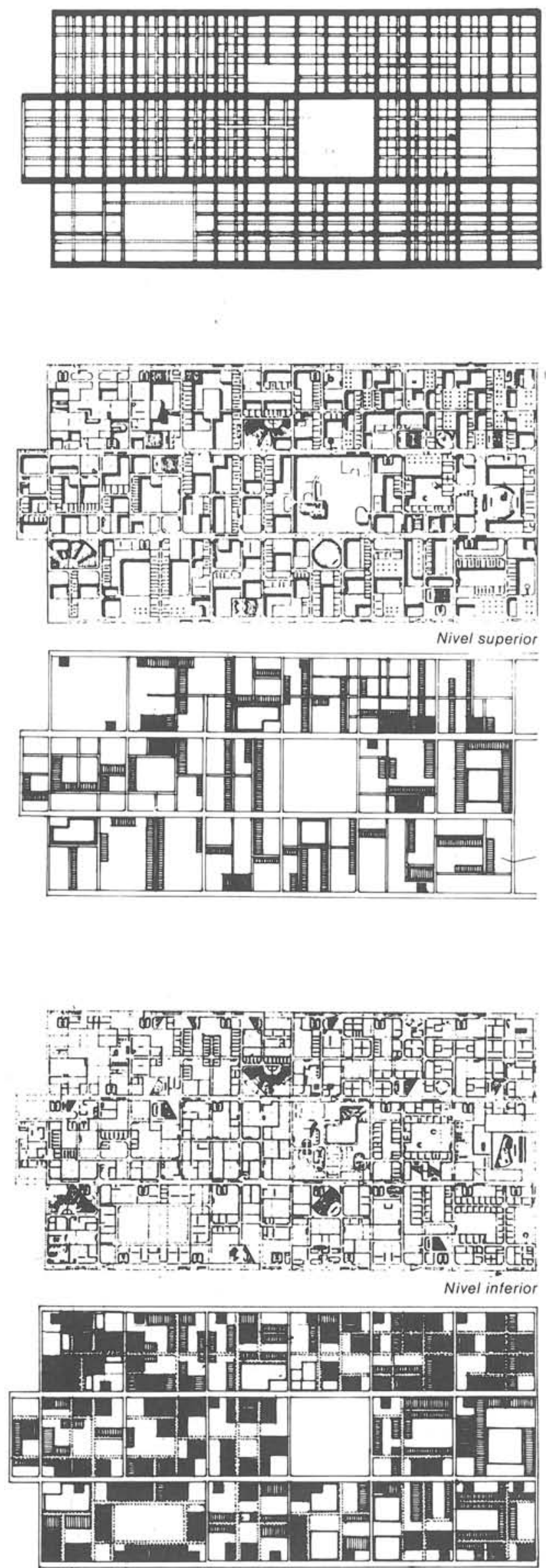

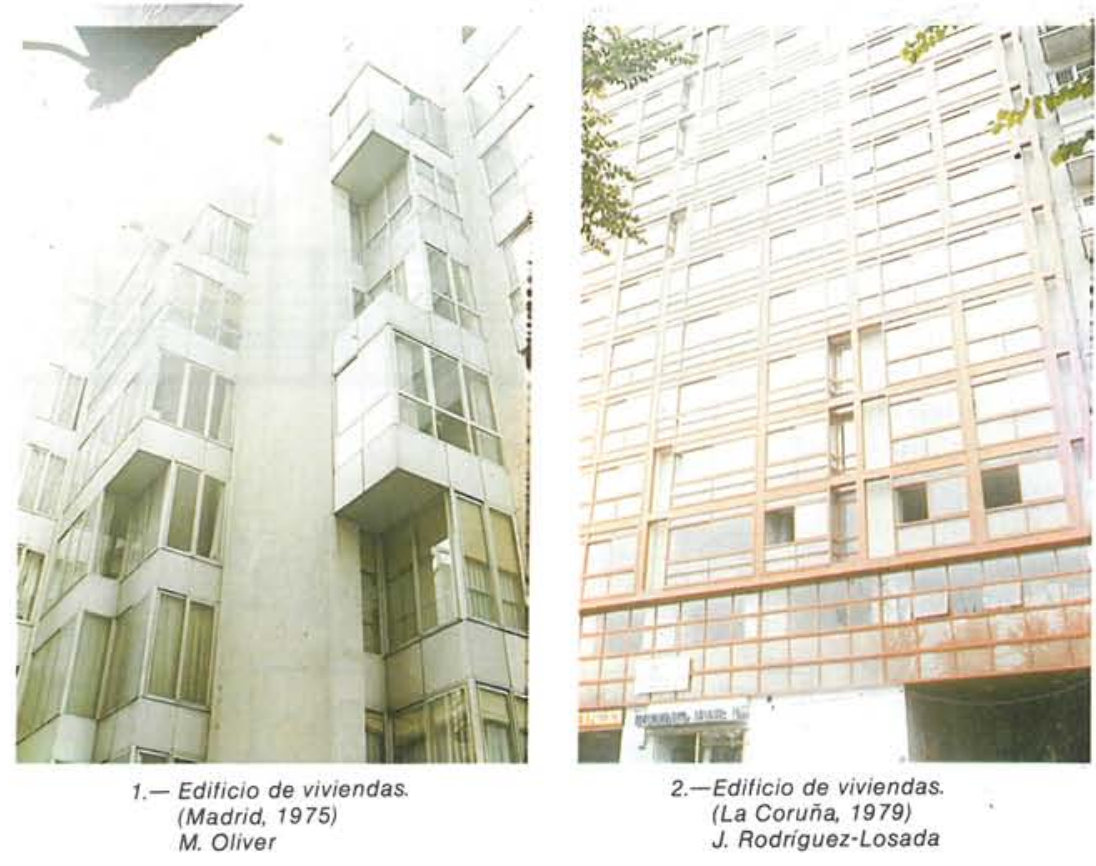

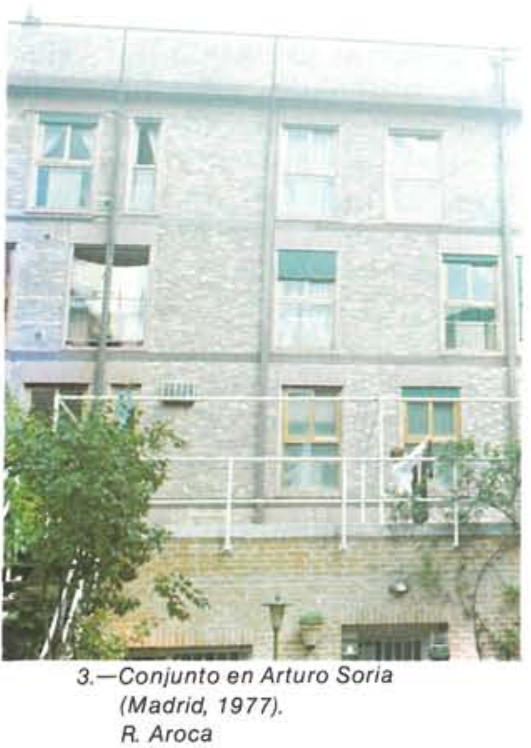

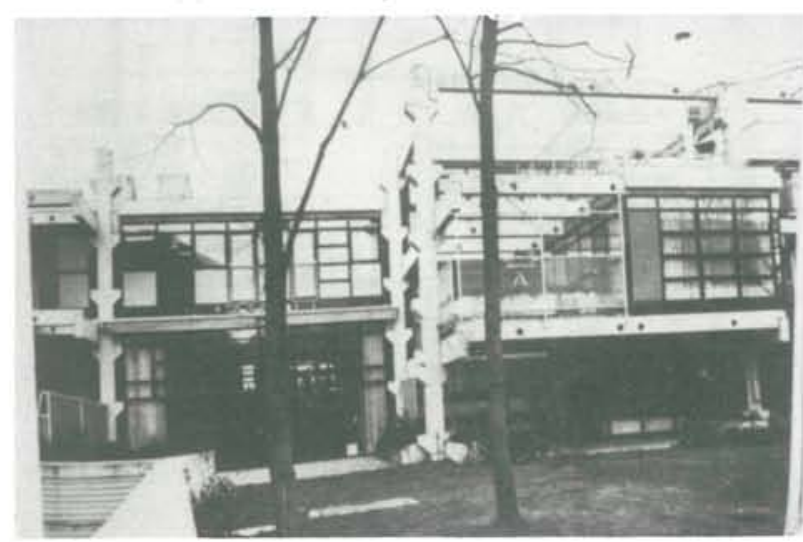

6

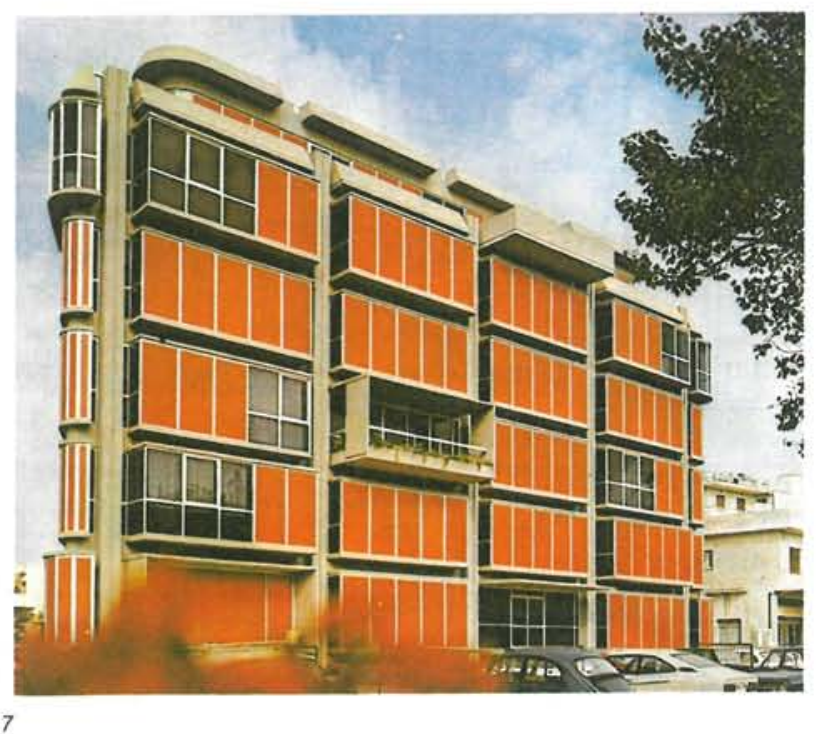

Dado que este artículo va encaminado a la presentación de los S3C para definir sus caracteres e implicaciones generales y no sólo tecnológicos, para el estudio de este punto se remite al lector al artículo "Morfología y funcionamiento del ensamble en construcción ligera», publicado en el n. ${ }^{\circ} 367$ de "Informes de la Construcción» y a su bibliografía.

\section{UN MERCADO}

Las condiciones de mercado que se proponen desde los sistemas de construcción por componentes compatibles (S3C, según la nomenclatura utilizada en la CEE), son distintas de las actualmente existentes en el mercado inmobiliario de la vivienda. El encarecimiento a que podría dar lugar el uso de tecnologías necesitadas de un gasto energético y una cualificación superior al de otras (fabricación de materiales y elementos constructivos «in situn), se ve compensado por la desaparición de los intermediarios, que encarecen enorme y constantemente el mundo de la construcción.

La primera figura profesional que desaparece es la del "constructor» o promotor por cuenta ajena (con toda su parafernalia administrativa y correspondiente mano de obra) que ya no es necesario, al permitir la propia naturaleza de los componentes que el propio fabricante se especialice en el montaje de los mismos, si no son fáciles de manejar por el usuario o bien que sea el propio usuario quien fácilmente lo haga (autoconstrucción).

De esta forma, la compra se hace directamente de fábrica, con montaje o no incluido, o bien el producto es comercializado por otros canales distintos de los del mercado inmobiliario (bricolage). 


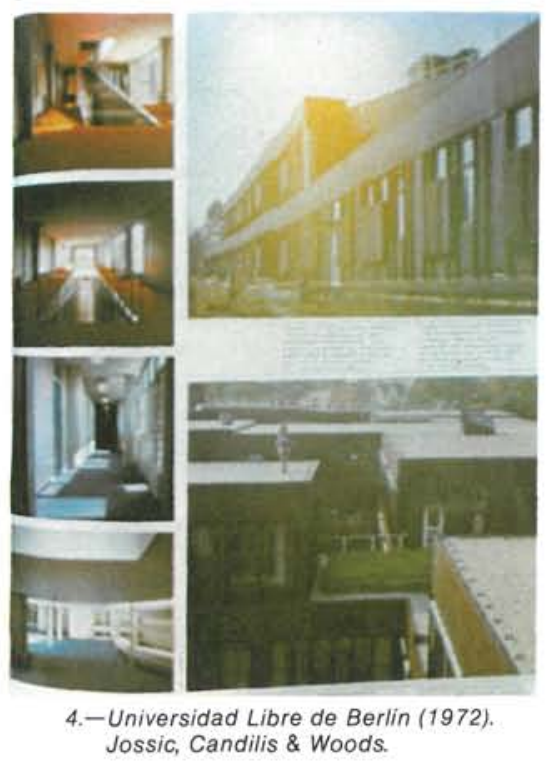

Así, junto a una mayor comodidad de producción y de uso, aparecen otras situaciones que, sin embargo, trastornan el aparato social en varios flancos:

- Desde el punto de vista económico, por abaratar los costes. Dado que actualmente la posibilidad de amortización de créditos e hipotecas se realiza con unos intereses y en unos plazos con los cuales realmente la inversión en el mercado inmobiliario supone a la larga un fuerte gasto en vez de un ahorro (inflación, etc.), parece más conveniente la compra de cualquier objeto de consumo. Entre estos objetos de consumo se encuentran los componentes constructivos compatibles, «más muebles» que «inmuebles», que desacreditan la posibilidad financiera de ese mercado al que trastocan.

- En relación al empleo de mano de obra, la construcción de edificios deja de ser una actividad, industrialmente atrasada, que constituye ese saco $\sin$ fondo que desde siempre ha corrido con la absorción de empleo no cualificado, siendo la Administración, como es sabido, la primera interesada en mantener tal situación, mientras no pueda variar las condiciones sociales y económicas en que el Estado se encuentra.

- Pero no acaban aquí las desdichas profesionales planteadas desde los S3C: la figura del proyectista (ingeniero o arquitecto) también se ve trastocada de lugar. De tener que responder directamente de un supuesto proyecto "sui géneris», pasaría a tener que responder del mismo a partir de las cualidades materiales y de organización que desde la propia industria garantiza la correspondiente consecución tipológica del componente. La otra aplicación del técnico, a la hora de definir el asentamiento residencial, estaría en el

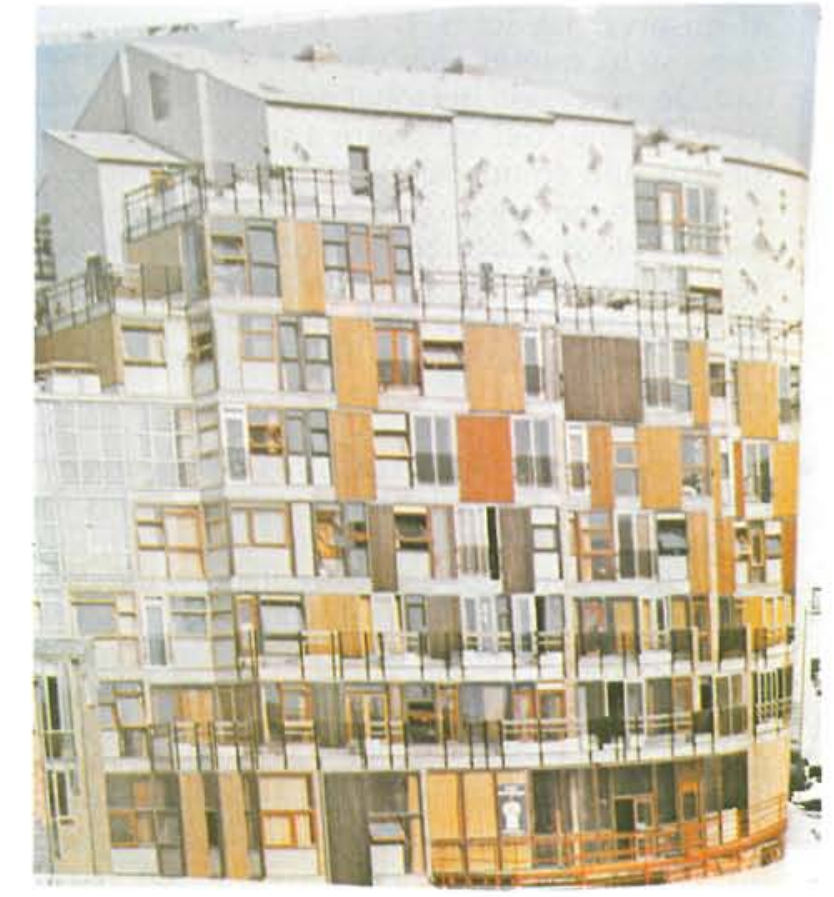

8

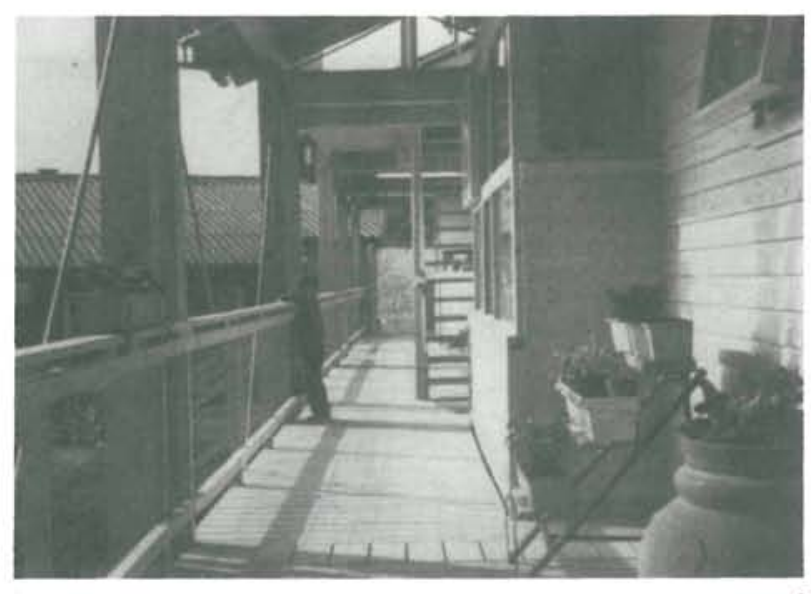


urbanismo, desde el cual se llegan a dar tales determinaciones tipológicas.

- Así, de la actual relación monocéntrica, en la que el constructor o promotor se relaciona unilateralmente con el resto de las partes, se pasaría a otrá lineal en la que el proyectista desde la industria y la industria directamente o a través del distribuidor están en contacto con el usuario, obteniendo éste, desde el urbanismo, las determinaciones tipológicas que necesita para "su construcción» - como ya ha quedado señalado-

- ¿Qué es lo que sucede cuando, utilizando algunas de las tecnologías planteadas desde los S3C, no se varían las condiciones de mercado?

Pues bien, a la vista está: sólo incipientes balbuceos de algo que quiere ser y se queda en pura apariencia superficial, en pura forma, que después de un gran esfuerzo sólo da pie a sugerir un contenido distinto del real.

Al observar las fotos 1, 2, 3, 4, 5, apreciamos cómo se ha querido dar ese aire de espontaneidad, de expresión personal desde el interior hacia el exterior del habitante a través de los elementos que componen la construcción, lo cual no ha sido, noes y no podrá ser con los procedimientos de producción empleados, que no han hecho sino dejar fija y petrificada cierta arbitraria y unilateral casuística formal, lo que, sin embargo, no ha sucedido en los casos de las $6,7,8$ y 9.

- Por una parte, en ningún caso se emplea una metodología espacial que permita hablar de los "órdenes abiertos» mencionados anteriormente. Por otra, los componentes empleados tampoco lo han sido desde la "prefabricación abierta», sino desde sistemas de "prefabricación cerrada», con la que el constructor, la industria y el proyectista han seguido manteniendo los lugares profesionales tradicionales, aprovechando las propiedades de los componentes compatibles para realizar «mecanos cerrados», gestionados a través de «meras subcontratas» que, en vez de gestionarse directamente $o$ indirectamente por

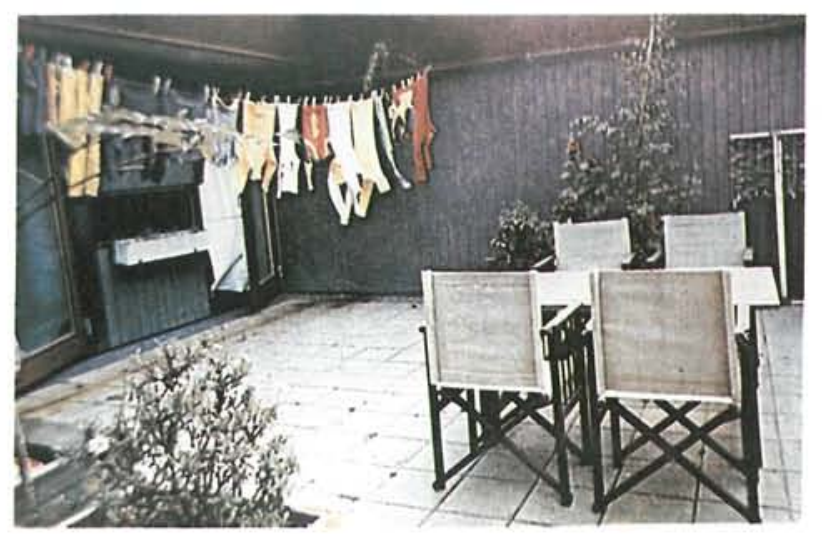

"Apartamento" en Dinamarca.

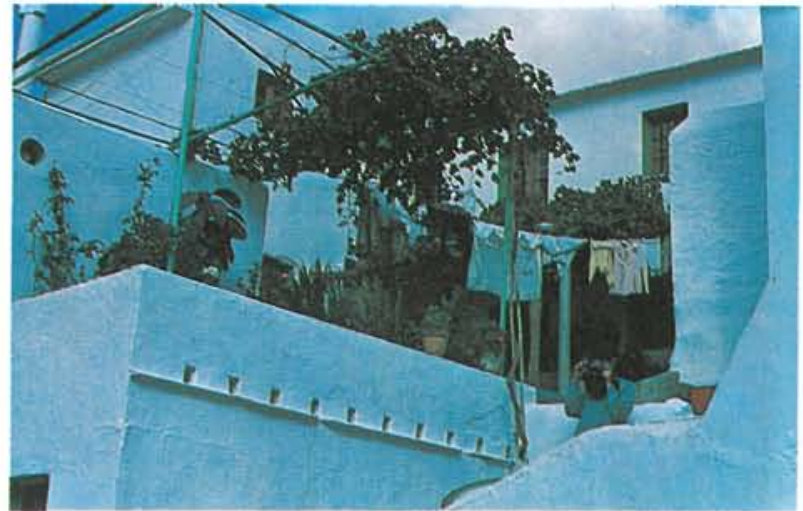

Vivienda vernácula en el Valle del Guadalhorce.

el usuario, lo son por ese «promotor por cuenta ajena».

Sólo en algunas promociones realizadas desde el cooperativismo, el proceso de gestión y contrata se acerca a lo propuesto desde los S3C; sin embargo, en estos casos es el proyectista quien al utilizar la industria de la construcción convencionalmente y no desde la "prefabricación abierta» produce nuevamente resultados "cerrados».

Al fin, el único logro y ya gran adelanto, dadas las circunstancias, es el empleo y exigencia de una modulación y coordinación dimensionales, que al menos permiten una cierta "flexibilidad de diseño» para el proyectista. En este sentido, hay que destacar el empeño de la Fundación Rafael Leoz que con su importante y no del todo reconocido esfuerzo continuo, mantiene los avances que desde la misma se han ido consiguiendo y difundiendo cara a la industrialización de la construcción.

\section{UN LUGAR}

Y en este punto se llega, al fin, a la aplicación real y material de una metodología, una tecnología y una economía: un resultado, una forma, un ambiente; un lugar en suma. Este viene implícito en los propios componentes y las tipologías por ellos definidas. Según esto no debería haber ningún problema en su aplicación automática, como siempre ha ocurrido con todas las normas que convencionalmente el usuario ha venido asumiendo a través de lo popular, de la tradición. Pero, ¿existe algún problema?: ¿La tradición?, ¿la propia costumbre?, ¿la antigua norma?, ¿el folklore? ¿Qué sucede cuando la «antigua norma» no es considerada o asumida por la «nueva norma»? ¿Cómo se produce este choque? ¿Qué clase de inadaptaciones y malentendidos se producen? ¿Por qué se producen?

De todos es sabido que ante la aparición de nuevos procedimientos y recursos, la sociedad siempre ha tendido a la imitación formal de lo ya conocido como aplicación automática de lo anterior. Así, ante la innovación tecnológica propuesta por los S3C, nos encontramos sorpresivamente con los mismos re- 

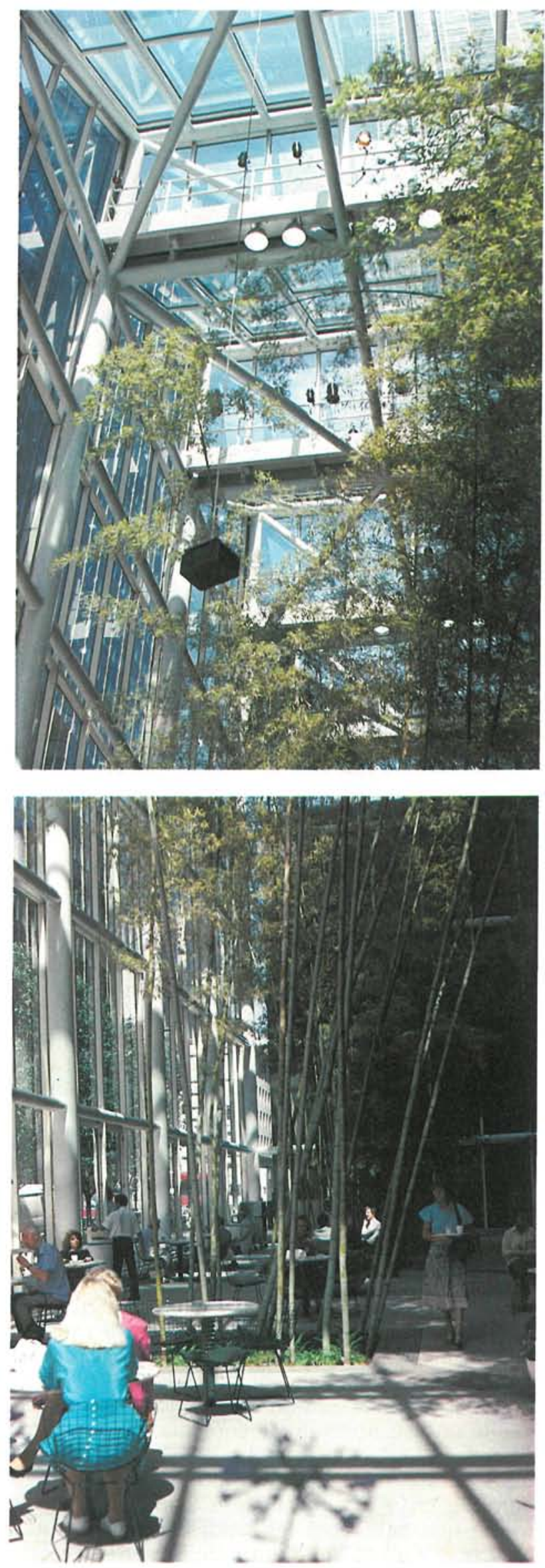

Hall urbano: "Soportal" en la 4." Av. N.Y.C. chazos y reacciones sociales que si estuviésemos a últimos del XIX, en pleno debate industrial, sumidos en las mismas diatribas y discusiones de W. Morris, A. Loos o Ruskin.

Sí, exactamente esto es lo que aún suecede cuando después de tanta polémica industrial y tanto maquinismo, la industria de la construcción sólo ha dado soluciones formales de aparente racionalismo, debidas al alto nivel de producción alcanzado, pero nunca al de calidad, que en ningún momento ha dejado de ser tosco y primitivo. Existen, no obstante, las honrosas excepciones de los maestros internacionales del movimiento moderno, que, sin embargo, no encontraron eco en el proceso industrial de producción, ya que como se ha señalado con respecto a la metodología, ni las Escuelas Oficiales prepararon técnicos para ello, ni la industria se vio obligada a servirse de los mismos.

En esta coyuntura, ni el ciudadano conoce nada mejor que lo antiguo, ni nadie pretende que lo haga, con lo cual nos vemos invadidos de malas imitaciones formales, traslaciones y dislocaciones de unas tecnologías en otras que, al hacer referencia a otros modos y usos, sólo consiguen utilizar la innovación por debajo de sus posibilidades, en deterioro y desprestigio de su imagen y resultados (Pág. 17).

El ambiente, el lugar es, por tanto, el eternamente resentido, aludido y puesto en tela de juicio ante lo dicho, pues:

- O bien se producen lo anteriormente expuesto: trasgresiones $\mathrm{y}$ «malentendidos convencionalismos".

- O bien se hace el consabido uso indiscriminado y aséptico de las nuevas tecnologías partiendo de sí mismas, sin ningún tipo de consideraciones culturales o geográficas, dando lugar a esa ingente cantidad de "honradas casetas modulares» -mal de nuestros días - a gran o pequeña escala, en "construcción ligera» o "pesada», que sólo basta observar levemente para ser calificadas (Pág. 17).

- O bien, por último, nos encontramos ante unas propuestas comprometidas desde los materiales y tecnologías empleadas, tratando de dar respuesta a la cultura y a la geografía en que se insertan desde el plano de lo sustancial y esencial y no en el meramente formal, encontrando el ya citado rechazo ante lo desconocido desde la definición convencional de confort.

A este último punto responden los prototipos de S3C aquí expuestos, de los que se ha tratado de dar a conocer precisamente su aspecto general, definición ambiental, cualidades espaciales, comportamiento bioclimático, acabados: habitabilidad en suma, a la hora de compararlos con la correspondiente "vivienda popular vernácula». Se han querido exponer estas características ya que si el demandante, el futuro usuario, es el primer descono- 


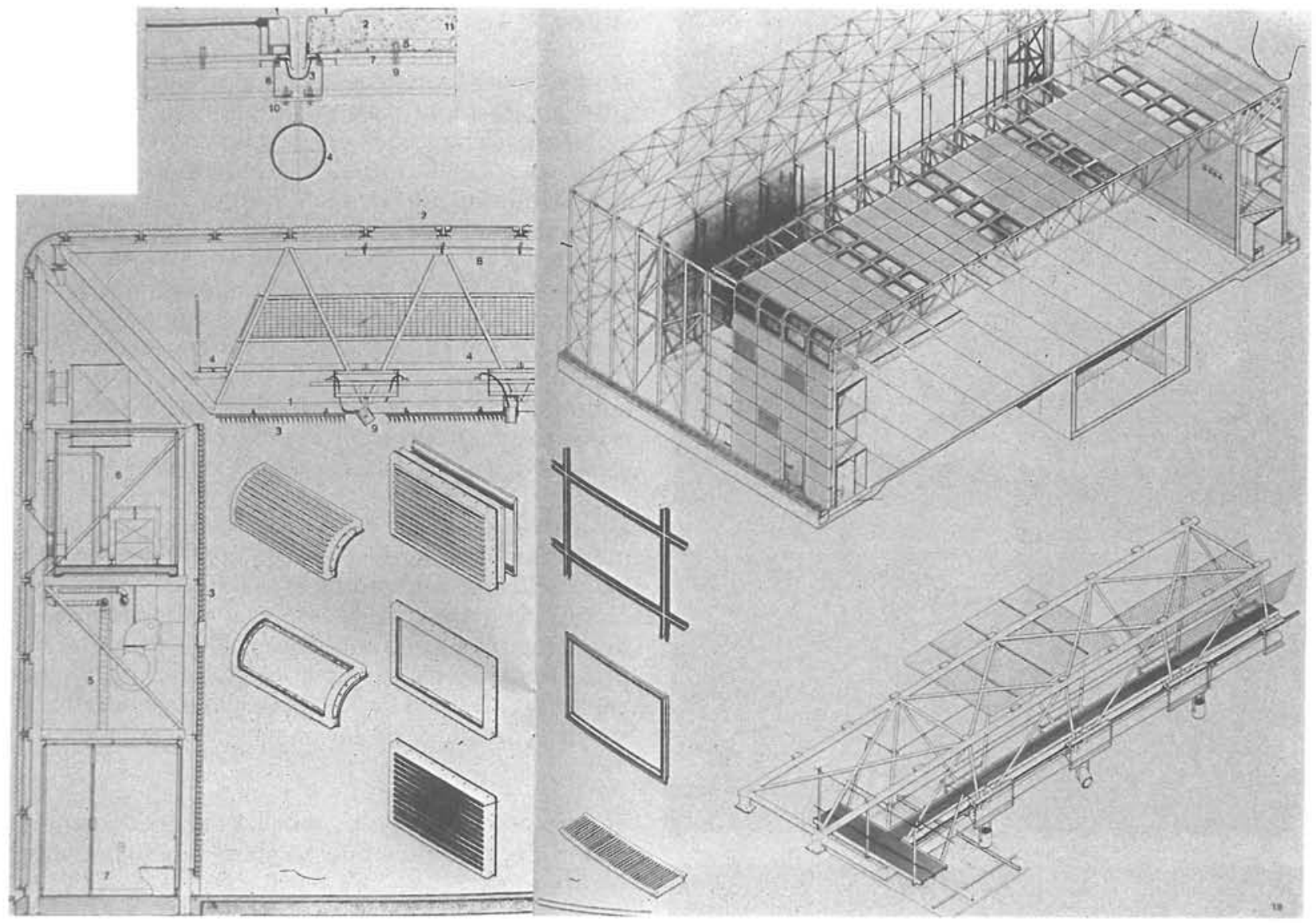

cedor de las cualidades del producto que se le ofrece - ventajas e inconvenientes-, difícilmente podrán llegar los S3C a cumplir su fin como «alojamiento popular contemporáneo», definido y construido por el propio usuario.

\section{UNA iTRANSFORMACION?}

Parece ser que los S3C, pese a todo, se mantienen en su lento pero continuo desarrollo, imponiéndose por sus ventajas reales en relación a los puntos señalados: confort, mercado, tecnología y metodología, frente a los inconvenientes también señalados (trastornos de carácter social todos ellos).

Que esto es así no sólo se refleja en el hecho material de su realización, sino también en la normativa y legislación internacional que les acompaña:

ISO: Organización Internacional de Normalización. ACC: Asociación de la Construcción y Componentes (1977).

SAR: Stiching Architecten Research (1965).

UEATEC: Union Européenne pour l'Agrément technique dans la construction.

que, como podemos apreciar partiendo de los ejemplos expuestos, pertenecen todos al área de los países desarrollados de Occidente (no se han realizado en relación al Japón y los países del Este). Todos estos países están en una situación económica distinta a la desarrollista de hace unas décadas, en la cual el mercado inmobiliario de la vivienda no tiene la misma demanda ni espectativas.

En ellos, de la política edificatoria de obra nueva se ha pasado a otra de rehabilitación o de aplicación real de verdaderos "Planes de Ordenación Territorial» que reciclen, reconviertan o revitalicen antiguos asentamientos y sectores económicos. Aún así, el nivel de vida de estos países sigue generando un parque importante de nueva vivienda, muy disminuido en relación a aquellos años, pero aún significativo (en el Estado Español se prevé la construcción durante el presente año de 250.000 nuevas viviendas de subvención oficial).

En estas circunstancias, parece contradictorio seguir proponiendo un continuo aumento de producción de material para la construcción. Sin embargo, no deja de tener sentido, ya que lo que se ofrece desde un S3C no es una tecnología determinada y cerrada, en relación al hecho del «inmueble», sino unos componentes que, en su "compatibilidad", admiten diversas posibilidades y adaptaciones, de forma que aumentan las salidas para la empresa desde el mismo momento de su producción y puesta automática en mercado (no son sólo aplica- 


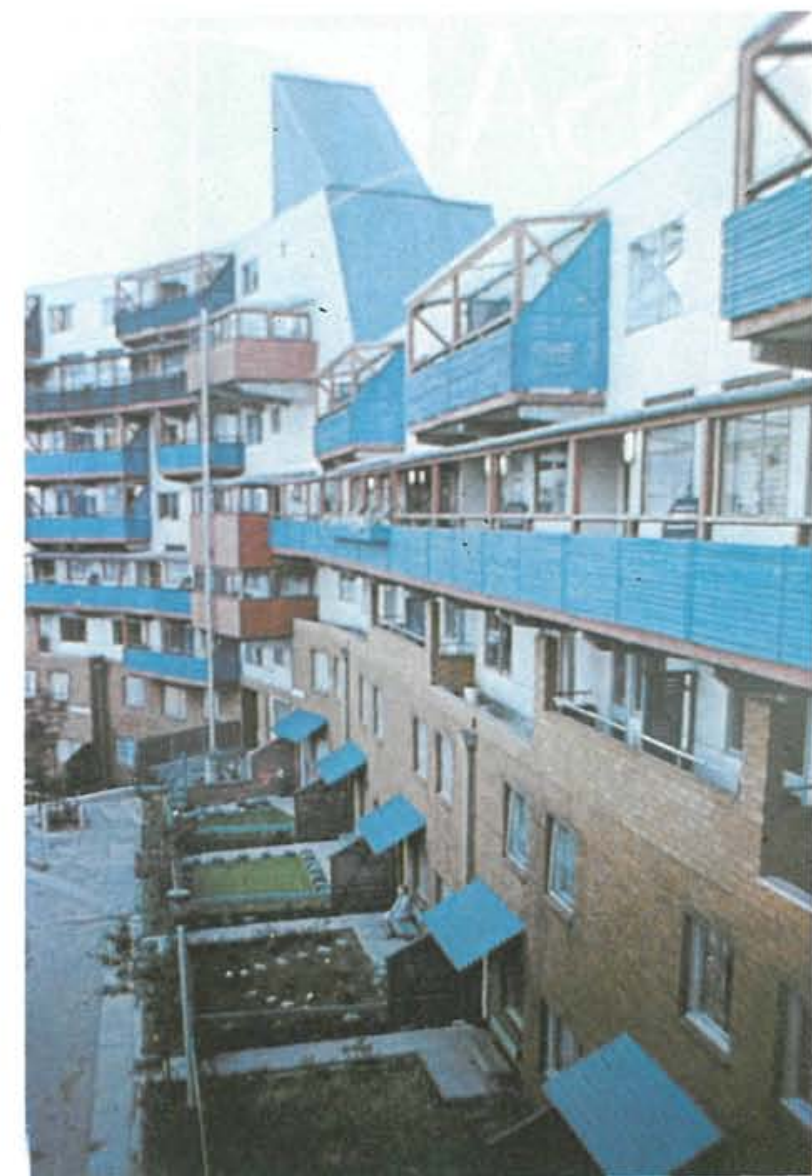

11

bles a construcciones de nueva planta, y no necesitan de intermediarios para su utilización).

Por último, dos ejemplos de construcción por componentes compatibles, ambos construidos en el mismo país (Gran Bretan̄a) y en fechas relativamente separadas: el Sainsbury Center (1981), de Foster Associates, y el Housing of Bryker (1964-68), de Erskine, cada uno en el extremo de una escala de sofisticación tecnológica, sirven para ilustrar este abanico de posibilidades (Figs. 10 y 11).

Antes de dar fin a estas líneas, sólo resta aclarar que las mismas no han querido ser un estudio tecnoló-

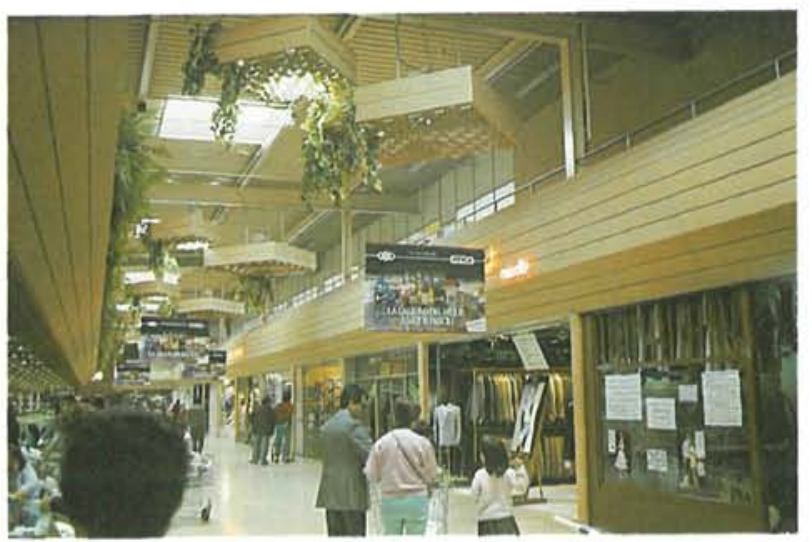

12 gico profundo del tema (para lo cual remitimos al lector a la bibliografía ya indicada en el apartado correspondiente), ni tampoco un exhaustivo compendio comparativo y evolutivo de antecedentes, que tendría mejor cabida desde la crítica arquitectónica (Mies V. der Roe, J. Prouvé, C. Eames, C. Price, A. de la Sota, J. L. Sert, ...); sino llevar a cabo la simple y llana exposición, desde el hecho arquitectónico en sí, de un fenómeno constructivo actual: "la construcción por componentes compatibles" que, aplicada al campo de la habitación humana, da lugar a unos hechos y resultados con sus consecuencias e implicaciones. Y llamar así la atención sobre el generalizado y paradójico fenómeno de un hábitat cotidiano y entorno próximo en donde a pocos metros, enfrentados por las orillas de cualquier autopista en el extrarradio de cualquier aglomeración urbana, coexisten dos construcciones aparentemente tan dispares y antagónicas como cualquier nave de hipermercado estándar (Foto 12) y unas interminables, idénticas, agotadoras y anónimas hileras de viviendas subvencionadas (Foto 13$)$.

De sus usos, sus materiales, sus rendimientos y sus metodologías, es de lo que aquí se ha tratado. Del interés que puedan suscitar en el usuario (que será el más favorecido), en la industria, en el mercado, en los profesionales, en la docencia, en el Estado, en suma, sería del que habría que hablar aún más. ¿Qué significa el progreso tecnológico ante tal situación de conocimiento, desinterés e inmovilismo?

M.R.G.

"Toda la belleza arquitectónica que he visto hasta el presente, sé que ha crecido gradualmente desde el interior hacia el exterior; desde las necesidades y el carácter del ocupante, que es el único constructor: desde alguna inconsciente veracidad y nobleza, sin dedicar al menos un pensamiento a la apariencia. Cualquier belleza adicional que pudiera producirse estará precedida por una casi inconsciente belleza vital. En un hombre construyendo su propia casa hay algo de la idoneidad del pájaro construyendo su propio nido."

Henry David Thoreau

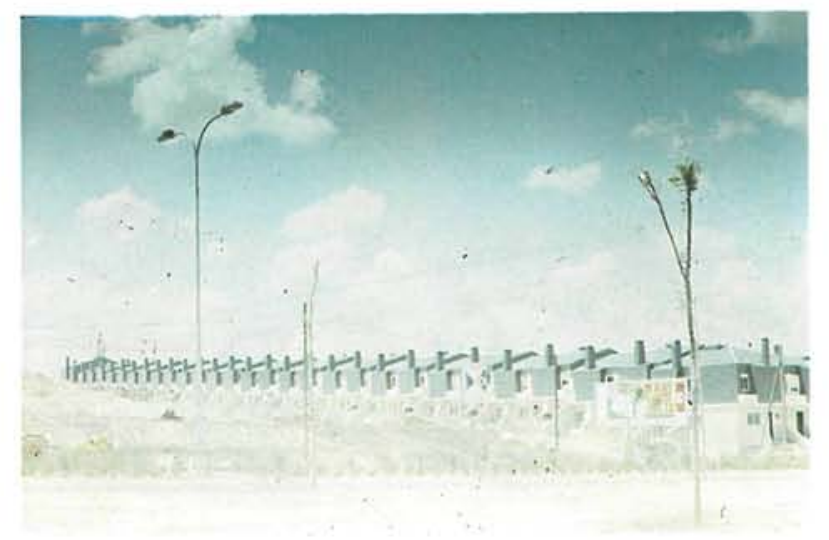

